\title{
System-based reliability analysis of stainless steel frames under gravity loads
} Itsaso Arrayago ${ }^{\mathrm{a}^{*}}, \mathrm{Kim}$ J.R. Rasmussen ${ }^{\mathrm{b}}$

${ }^{a}$ Dept. of Civil and Environmental Engineering, Universitat Politècnica de Catalunya, Spain

\section{${ }^{b}$ School of Civil Engineering, The University of Sydney, Australia}

* Corresponding author: Itsaso Arrayago, Jordi Girona 1-3, Building C1, 08034 Barcelona, Spain, itsaso.arrayago@upc.edu

\section{ABSTRACT}

Current structural codes for steel and stainless steel structures such as AISC 360-16, AISC 370-21, AS/NZS 4100 and Eurocode 3 are based on the traditional two-step member-based design approach, in which internal actions are first obtained from a structural analysis, usually elastic, and the strength of each member and connection is subsequently checked using a structural design standard. However, the most recent versions of these standards already incorporate preliminary versions of the direct, or one-step, system-based design alternative, which is based on the design-by-analysis concept and allows evaluating the strength of structures directly from numerical simulations, although the standards in their current form do not provide reliability requirements for structural systems. Therefore, it is necessary to build a rigorous structural reliability framework to investigate acceptable target reliability indices for structural systems and to provide adequate system safety factors and system resistance factors. While this framework has been developed based on advanced Finite Element analysis for hot-rolled and cold-formed carbon steel structures in recent years in the form of the Direct Design Method (DDM), the framework does not exist for stainless steel structures. This paper presents an extension of the DDM to the analysis of stainless steel structures, in which system reliability calibrations are presented for six stainless steel portal frames under gravity loads covering the three most common stainless steel families and different failure modes using advanced numerical simulations. From the derived reliability calibrations, suitable system safety factors $\gamma_{\mathrm{M}, \mathrm{S}}$ and system resistance factors $\phi_{\mathrm{S}}$ are proposed for the direct design of stainless steel frames in the European, US and Australian design frameworks under gravity loads.

\section{KEYWORDS}

advanced analysis; probability-based design; reliability calibrations; stainless steel structures; structural reliability 
- Extension of the Direct Design Method to stainless steel structures is presented.

- Rigorous reliability framework is built and presented for the analysis of stainless steel structures under gravity loads.

- Six cold-formed stainless steel portal frames are analysed, including different stainless steel families and failure modes.

- System reliability calibrations are presented for the Eurocode, US and Australian design frameworks, covering different live-to-dead load ratios.

- System safety factors $\gamma_{\mathrm{M}, \mathrm{S}}$ and system resistance factors $\phi_{\mathrm{S}}$ are proposed for the target reliability indices typically adopted in national design frameworks.

\section{INTRODUCTION}

The most commonly accepted approach for determining structural reliability, i.e. the probability of failure of a system of structural members, is to assess the reliability of a structural system by requiring the probability of loads Q exceeding the structural resistance R (or reaching a certain limit state more generally) to be less than an adopted target value, in which models for resistance and loading are individually defined. Current design of structures is based on traditional limit state criteria following a two-step approach where internal actions are first determined from a structural analysis, usually elastic, and limit states are subsequently checked for members and connections such that the ultimate capacity of the structure is reached when the first member or connection reaches its ultimate limit state. Provisions for these checks are given by structural codes for the particular materials, e.g. steel [1-4], in which design parameters and their random variations are modelled by nominal or characteristic values based on partial coefficient methods. However, the exponential growth of the computational power of standard desktop computers and rapid advances in design software during the past decades have made it possible to accurately predict the behaviour and failure of complex structural systems, providing engineers with the opportunity to progress from the current two-step member-based design method to a direct system-based design-by-analysis approach. One of these system-based methods is the Direct Design Method (DDM), which is based on a geometric and material nonlinear (advanced) analysis that 
incorporates effects known to substantially affect the behaviour and strength of systems, like residual stresses and geometric imperfections. Typically, the analysis is performed using the Finite Element Method. With the DDM, the strength of structures can be directly evaluated from numerical simulations, eliminating the need for subsequently checking member and connection resistances. The DDM ensures a more uniform reliability of the complete structure across a range of structural systems [5], can be applied equally to simple and complex geometries, and as such encourages innovation, and has the potential to lead to lighter and more economical designs [6-9].

A few structural codes for carbon steel (AS/NZS 4100 [3], AISC 360-16 [4]) and stainless steel (AISC 370-21 [10]) already incorporate provisions for analysis-based design, but do not provide adequate reliability requirements for structural systems. In this context, a new part of Eurocode 3 is being developed for steel structures, Part 1-14: Design assisted by finite element analysis [11], which will include provisions for how to create finite element models to be used in design. The design equations in these cases are given by Eq. 1 and Eq. 2 for the Eurocode and the US/Australian design frameworks, respectively, where $\mathrm{R}_{\mathrm{k}}$ and $\mathrm{R}_{\mathrm{n}}$ are the characteristic and nominal resistances of the system, respectively, $Q_{\mathrm{ki}}$ and $\mathrm{Q}_{\mathrm{ni}}$ denote the characteristic and nominal structural loads, respectively, $\gamma_{\mathrm{i}}$ is the corresponding load factor and finally, $\gamma_{\mathrm{M}, \mathrm{S}}$ and $\phi_{\mathrm{S}}$ are the safety factor and the resistance factor of the system, respectively.

$$
\begin{gathered}
\frac{\mathrm{R}_{\mathrm{k}}}{\gamma_{\mathrm{M}, \mathrm{s}}} \geq \sum \gamma_{\mathrm{i}} \mathrm{Q}_{\mathrm{ki}} \\
\phi_{\mathrm{s}} \mathrm{R}_{\mathrm{n}} \geq \sum \gamma_{\mathrm{i}} \mathrm{Q}_{\mathrm{ni}}
\end{gathered}
$$

Although the abovementioned standards require that "a comparable or higher level of reliability" than existing member-based provisions be achieved when designing by analysis, they do not include provisions or guidance on acceptable target reliability indices $\beta_{0}$ for structural systems, nor do they provide system-based safety factors or give guidance on how to determine these. Thus, a framework for determining appropriate system safety factors $\gamma_{\mathrm{M}, \mathrm{S}}$ or system resistance factors $\phi_{\mathrm{S}}$ based on rigorous structural reliability considerations is fundamental for the variety of structural types and materials covered by these design codes. In recent years, design recommendations have been proposed for hot- 
rolled carbon steel frames [6,7], cold-formed steel frames [8,9], steel storage rack frames [12] and steel scaffolds [13] in the framework of the Direct Design Method. However, such reliability analysis framework does not exist for stainless steel structures. This is being addressed in the NewGeneSS project [14], which is developing the basis of the DDM design method for stainless steel structures.

With significant strain-hardening properties, high mean-to-nominal resistance ratios (overstrength ratios) and noticeable nonlinear stress-strain response, stainless steel structures require independent reliability calibrations [15-18]. While these are structures with potentially higher resistance reserve due to strain-hardening and high overstrength ratios, the material nonlinearities can also cause premature stiffness losses that can increase deflections and further amplify second-order effects $[18,19]$. This is apparent in international design standards, which provide different design equations and safety factors (or resistance factors) for equivalent design situations for stainless steel and carbon steel members, with the factors for stainless steel structural members being generally more conservative. The Eurocode Standard for stainless steel structures prEN 1993-1-4 [2] has traditionally recommended a partial safety factor of $\gamma_{M}=1.10$ for cross-section and member resistances, while the $\gamma_{M}$ value recommended for carbon steel in prEN 1993-1-1 [1] is 1.00, although different values may be specified in the different National Annexes. The difference in the recommended partial safety factors can be attributed partly to the considerably more extensive pool of data available for carbon steel structures and partly to the lower variability exhibited by structural steels in terms of material properties. Conversely, the upcoming versions of the AISC 370-21 [10] and ASCE 8 [20] specifications adopt a resistance factor of $\phi=0.90$ for the design of stainless steel members, which is equivalent to a safety factor of about $1 / 0.90=1.11$ and equal to the resistance factors prescribed for carbon steel structural members in AISC 360-16 [4] and AISI S100-16 [21]. Nevertheless, the superseded ASCE 8 specification adopted a resistance factor of $\phi=0.85$ (equivalent to safety factors of $1 / 0.85=1.18$ ) in its 2002 version. Finally, while the Australian AS/NZS 4100 [3] Specification requires a resistance factor of $\phi=0.90$ to be adopted for carbon steel members, the current AS/NZS 4673 [22] Specification uses the value of $\phi=0.85$ for the design of cold-formed stainless steel cross-sections and members. 
This paper presents the derivation of appropriate system safety factors $\gamma_{\mathrm{M}, \mathrm{s}}$ and resistance factors $\phi_{\mathrm{s}}$ to adopt in the design-by-advanced analysis of stainless steel cold-formed portal frames subjected to gravity load combinations. Section 2 describes the characteristics of the nominal frames considered in the analysis, while in Section 3, Finite Element (FE) models developed for both nominal frames and subsequent simulation studies are described, including the validation of the FE model. In Section 4, the full reliability analysis framework for stainless steel frames is described, covering the probabilistic models for the different random variables considered and the system reliability assessment. Finally, the reliability calibration results are presented and discussed in Section 5, and suitable system safety factors $\gamma_{\mathrm{M}, \mathrm{S}}$ and resistance factors $\phi_{\mathrm{S}}$ are proposed for the Eurocode, US and Australian design frameworks investigated.

\section{SYSTEM STRENGTH OF STAINLESS STEEL FRAMES}

\subsection{DESCRIPTION OF NOMINAL FRAMES}

This study considers single-storey, single-bay stainless steel portal frames of the type shown in Figure 1. Such portal frames are typically found in industrial settings and comprise the great majority of steel buildings constructed [23]. The study on stainless steel frames presented in this paper is based on six different frames, for which the typical nominal dimensions for the overall layout were chosen to reproduce frame geometries commonly used in practise [24]. The portal frames are assumed to be connected through five uniformly distributed longitudinal purlins along the rafters and longitudinal bracings at the mid-height of the columns, as shown in Figure 1, as well as a wind bracing system in the roof planes and the vertical walls. All portal frames comprised members made from cold-formed rectangular hollow section (RHS) tubes, with the same section geometries for columns and rafters. The six frames covered the three most common stainless steel families: while for Frames 1 and 2 the common austenitic stainless steel grade EN 1.4301 (ASTM 304) was chosen, Frames 3 and 4 correspond to the typical duplex grade EN 1.4462 (ASTM 2205) and Frames 5 and 6 represent the ferritic grade EN 1.4003 (ASTM UNS S40977).

The nominal overall frame geometries (span length $\mathrm{s}$, heights at the eaves $\mathrm{H}_{1}$ and at the roof ridge $\mathrm{H}_{2}$ ) and cross-section definitions (cross-section height $\mathrm{H}$, width $\mathrm{B}$ and thickness $\mathrm{t}$ ) for each frame are 
summarized in Table 1, and were selected to produce a variety of failure modes, as discussed in Section 2.2. Note that Frames 1, 3 and 5 have the same overall frame and cross-section definition but correspond to different stainless steel families to illustrate the effect of the material in system reliability calculations. The definitions of initial imperfections, connection stiffness, material properties and residual stresses adopted in the nominal stainless steel portal frames investigated in this paper are based on relevant standards and the literature, and are described in detail in the following sections.

\subsubsection{Initial geometric imperfections}

141 Initial geometric imperfections relevant to cold-formed stainless steel frames include frame out-of142 plumbness imperfections, member out-of-straightness imperfections and local cross-sectional imperfections. These three types of initial imperfections can influence the strength and stiffness of stainless steel frames, although frame and member imperfections generally cause the most significant reductions in failure loads of the tubular type of members considered in this paper. Consequently, relevant international design standards include clauses providing design values for these initial geometric imperfections and requirements on how to include them in numerical simulations, with small differences among the standards. When determining the strength of the nominal frames, the most critical combination of the different directions of each geometric imperfection type (i.e. combination resulting in the lowest frame strength) was determined and adopted for the nominal structural models. In determining frame imperfections in the Eurocode design framework, prEN 1993-1-14 [11] refers to prEN 1993-1-1 [1], which defines a design (or nominal) value of the basic out-of-plumbness angle $\phi$ of $1 / 200$, and adopts a nominal member out-of-straightness imperfection with a shape derived from the relevant elastic buckling mode and an amplitude $\mathrm{e}_{0}$ of $\mathrm{L} / 1000$ when local imperfections are combined with member imperfections, where L is the length of the member. Alternatively, AS/NZS 4100 [3], AISC 360-16 [4] and AISC 370-21 [10] specify a slightly lower out-of-plumbness angle $\phi$ of 1/500 for advanced analysis, with the same nominal member imperfection amplitude $\mathrm{e}_{0}$ of $\mathrm{L} / 1000$ with a halfsinusoidal shape along the member length. The design values adopted in the nominal models for frame and member imperfection amplitudes are reported in Table 1. 
While the Eurocode design framework requires local imperfections to be incorporated in the developed finite element models [11], the nominal frame models specified in the US and Australian frameworks do not include local imperfections. However, since prEN 1993-1-14 [11] only provides guidance on the magnitudes of local imperfections for outstand elements and distortional buckling in cold-formed sections, the local imperfection amplitudes $\mathrm{w}_{0}$ given by the modified Dawson \& Walker model [25] have been adopted in this paper, as shown in Table 1 for the different cross-sections considered. It should be noted that even for those cases in which local imperfections do not need to be explicitly incorporated in the nominal models (i.e. US and Australian frameworks), the structural analysis models developed in this study for the reliability calibrations incorporate all three imperfections (as described in Section 3) and thus, the influence of the local imperfections is implicitly present in the derived system safety factors (or system resistance factors).

\subsubsection{Connection behaviour}

Joints of portal frames comprising cold-formed hollow section tubes are complex and often use welded connection solutions, as defined in the CIDECT design guide for RHS connections [26]. The guide includes recommended details for unstiffened and stiffened welded knee connections suitable for rigid portal frames. According to the guide, the rotation capacity of unstiffened connections can be low and thus, stiffened knee connection should be used in structures requiring significant rotational capacity. Test data for stiffened welded knee connections is scarce and limited to carbon steel hollow sections [27-29]. The moment-rotation curves provided in [27] can be reasonably described by a bi-linear curve similar to that shown in Figure 2, which is defined by two stiffness parameters, $\mathrm{K}_{1}$ and $\mathrm{K}_{2}$, and two moment capacities, $\mathrm{M}_{1}$ and $\mathrm{M}_{2}$. Results reported in [27] indicate that while $\mathrm{M}_{1}$ remained below the plastic capacity of the cross-sections (at approximately $75-80 \%$ levels), these stiffened welded connections reached moments exceeding the section flexural capacity by $110-155 \%$. Although there are no equivalent studies of stainless steel stiffened welded connections, recent tests on stainless steel portal frames with RHS sections reported in [30,31] adopted welded column-to-rafter connections with auxiliary steel plates equivalent to those defined in [26,27]. For the connections at the bases in $[30,31]$, steel plates were welded to the bottom edges of the columns, which were then bolted to a pair of load 
bending moments comparable to the flexural strength of the sections were attained for some of the

189 specimens at the column-to-rafter (eave) connections.

190 Considering these findings, the connections adopted for the present study represent the behaviour of stiffened welded connections equivalent to those described in [26,27,30,31], and following the approach adopted in [9], the moment-rotation responses of the connections at column bases, eaves and apex have been modelled using the bi-linear curve shown in Figure 2. The parameters defining the nominal connection responses for each frame are summarized in Table 1. The parameters were chosen from the stiffness values reported in [30,31] for similar stainless steel RHS connections and moments $\mathrm{M}_{1}$ and $\mathrm{M}_{2}$ were adapted from [27] to the flexural capacities of the cross-section geometries and materials adopted in this study. Note that this study does not consider joint failure but assumes the ultimate moment and ductility capacities of the joints are not reached at the failure states of the frames.

\subsubsection{Material properties}

Stainless steel alloys show pronounced nonlinearity in their stress-strain response with considerable strain-hardening, which is most commonly described through two-stage material models [32,33] and a series of material parameters. Basic nominal material properties for different stainless steel grades such as the Young's modulus $\mathrm{E}$, yield stress $\mathrm{f}_{\mathrm{y}}$, ultimate tensile strength $\mathrm{f}_{\mathrm{u}}$ and strain-hardening exponent $n$ are provided in the different structural standards for the Eurocode design framework [2,34], the US framework [20] and the Australian framework [22]. Additional guidance on the modelling of the nonlinear stress-strain response of stainless steel alloys (i.e. to estimate the required additional material parameters such as ultimate strain $\varepsilon_{\mathrm{u}}$ and the strain-hardening exponent $m$ ) is provided in $[10,11,20]$, which was based on the comprehensive studies conducted in [32,33]. Although the yield stress $f_{y}$ and ultimate tensile strength $f_{u}$ values provided in structural and material standards correspond to the unformed material, it is well known that cold-formed structural sections undergo significant plastic deformations during manufacturing, which result in a notable increase of the yield stress and a reduction in ductility [36]. Thus, some international design standards already include predictive models to account

213 for these yield stress enhancements [2,34], based on the work presented in [36]. With the aim of 214 developing realistic advanced nominal models, adhering to the provisions given in the different 
standards, the enhanced material properties of the cold-formed tubes as per [2,34] have been considered 216 in the nominal frame models developed in this study.

217 The values of the nominal material parameters for the stainless steel grades chosen for the present study (austenitic grade EN 1.4301/ASTM 304, duplex grade EN 1.4462/ASTM 2205 and ferritic grade EN 1.4003/ASTM UNS S40977) are summarized in Table 2, Table 3 and Table 4 for the Eurocode, US and Australian design frameworks, respectively. Basic material parameters have been directly extracted from the corresponding structural and material Standards, while the remaining parameters, including the enhanced nominal yield stress $\mathrm{f}_{\mathrm{y} \text {,enh }}$, the ultimate strain $\varepsilon_{\mathrm{u}}$ and the strain-hardening exponent $m$ have been calculated based on the nominal basic material properties and the predictive models given in $[10,11,20]$ and $[2,34]$, respectively. The nominal frame models for the three design frameworks have been built considering enhanced material properties as per the predictive models in $[2,34]$ because considering the basic material parameters for cold-formed elements would result in too conservative predictions of the nominal system strength. Note that since duplex stainless steel grades are currently out of the scope of the AS/NZS 4673 [22] Specification, the basic material properties given in the ASCE 8 [20] Specification for the ASTM 2205 grade have been adopted for Frames 3 and 4 in the Australian design framework (see Table 4). In the same line, the nominal yield stress $\mathrm{f}_{\mathrm{y}}$ and ultimate tensile strength $f_{u}$ values adopted in this study for the ferritic frames (Frames 5 and 6 ) in the US framework were extracted from the AS/NZS 4673 [22] Specification, since grade EN 1.4003 is not currently covered by ASCE 8 [20].

\subsubsection{Residual stresses}

Residual stresses in cold-formed stainless steel structural sections are generated during the fabrication processes due to non-uniform plastic deformations, and they can significantly affect the resistance of stainless steel structures [37]. For the cold-formed rectangular hollow section members considered in this paper, membrane residual stresses are low in magnitude and have been shown to have a negligible influence on the structural response, while bending residual stresses are more important [37]. According to prEN 1993-1-14 [11], FE models should include the effect of residual stresses as initial strains or stresses following the appropriate patterns for each section and material type. Similarly, the 

models shall include the influence of residual stresses by explicitly modelling these effects in the analysis or by reducing the stiffness of all structural components. prEN 1993-1-14 [11] defines residual stress patterns for a number of cross-section and material types, but since no pattern is given for coldformed stainless steel SHS and RHS sections, the model proposed in [37] has been adopted in this study. It assumes residual stress magnitudes equal to $0.37 \mathrm{f}_{\mathrm{y}}$ for the corner regions of the cross-section and $0.63 \mathrm{f}_{\mathrm{y}}$ for the flat regions, with a rectangular block distribution through thickness and tensile stresses at the outer surfaces of the sections. The same residual stress pattern has also been adopted for the nominal system models developed for the Australian and US design frameworks. In all cases, bending residual stresses were introduced as initial stresses in the finite element models, further details of which are provided in Section 3.1.

\subsection{FAILURE BEHAVIOUR OF NOMINAL FRAMES}

The overall dimensions and support conditions of the six stainless steel frames investigated in this paper were chosen to cover different failure modes under gravity loads. It is worth mentioning that although the ultimate failure loads corresponding to the nominal frames for each of the design frameworks investigated were slightly different, as it is further discussed in Section 5.1, the failure modes observed for each frame were essentially identical for the three design frameworks considered.

Frames 1, 3 and 5 representing austenitic, duplex and ferritic stainless steel alloys, respectively, have the same overall and cross-section dimensions, with relatively low spans and heights, and compact cross-sections (see Table 1). These frames showed non-sway failure modes associated with spatial yielding at the critical cross-sections, and will allow evaluating the influence of the stainless steel material properties, including strain-hardening, and internal force redistribution in reliability calibrations. The frames showed considerable vertical deflections at the apex sections, while the observed lateral drifts were small. Important influence of material nonlinearity was observed for the

266 frames, especially for the austenitic Frame 1, with a considerable redistribution of internal forces. At

267 the ultimate limit state of the austenitic and ferritic Frames 1 and 5, spatial plastic hinges first formed in the columns near the left and right eave connections, followed by plastic hinges near the apex. The 
failure of the frames occurred soon thereafter when yielding initiated at the base of the right columns.

270 Despite having the same nominal cross-section, Frame 3 showed remarkably lower redistribution 271 capacity when compared to the equivalent Frames 1 and 5, owing to the considerably higher local slenderness of the cross-section due to the higher yield stress exhibited by duplex stainless steel grades (see Table 2, Table 3 and Table 4). Thus, spatial plastic hinges featuring local buckling deformations were observed sequentially near the right eave, left eave and apex connections for Frame 3, and the frame failed before any yielding was observed at the right column base. In line with the findings reported in [27], local failures were observed on the inside of the eaves connections at advanced stages of frame deformations, and formed in the columns adjacent to the connections. Stresses and local deformations were more pronounced at the right eave for Frames 1,3 and 5, despite the fact that the loading configuration adopted for these frames was symmetric. Since initial out-of-plumb imperfections were introduced towards the right side of the nominal frames, slightly non-symmetrical failure modes were observed. These imperfections were not sufficient to trigger sway failure modes, given the high rotational stiffness of the bases, but caused slightly higher internal forces at the right columns.

On the other hand, Frames 2, 4 and 6 corresponding to austenitic, duplex and ferritic stainless steel alloys exhibit longer spans and pinned support conditions (see Table 1), which resulted in in-plane sway failure modes and allowed evaluating the influence of interaction between material nonlinearities and second order effects in reliability calibrations. The cross-sections comprising these sway frames showed local slenderness values close to the limiting cross-section slenderness between fully effective and slender cross-sections, and thus they were not capable of developing strain-hardening or bending moment redistribution. These frames showed large lateral drifts and vertical deflections at the apex at their respective ultimate limit states, as well as interaction between second order effects and material nonlinearities, particularly for the austenitic Frame 2. Failure occurred when the capacity of the critical cross-sections at the right eave joints was reached, attaining stress levels similar to the corresponding 
imperfections of the nominal frames were introduced towards the right-side of the frames, which

296 triggered the failure of the frames to occur near the right eave connection.

\section{3. FINITE ELEMENT MODELS AND SIMULATIONS}

\section{3.1. DEVELOPMENT OF FINITE ELEMENT MODELS}

299 Numerical simulations to estimate the system strengths of stainless steel frames were carried out based on advanced finite element models developed using the general-purpose software ABAQUS [38]. Duopitched single-storey, single-bay portal frames equivalent to those described in Section 2, with members comprising cold-formed rectangular hollow sections, were modelled using S4R shell elements. These elements have been widely used in the simulation of cold-formed stainless steel members $[39,40]$ and frames [31].

Portal frame models consisted of four independent tubes representing column and rafter members, which were then connected to each other with a system of connector elements available in the ABAQUS library [38] (rigid BEAM, HINGE and UJOINT connector elements), following the approach adopted in [9]. BEAM type connectors provide a rigid beam connection between two nodes, while HINGE type connectors join the position of two nodes, provide a constraint between one rotational degree of freedom and a rigid behaviour for the remaining degrees of freedom. UJOINT type connectors also join the

311 positions of two nodes, but provide a universal constraint between two rotational degrees of freedom.

312 Both HINGE and UJOINT type connector elements allow assigning different types of user-defined connection behaviours (e.g. elastic, plastic, friction, damage, etc.), but while the UJOINT connector element provides a constraint in two rotational degrees of freedom (i.e. rotations about the out-of-plane and in-plane axes), the $H I N G E$ connector element only constrains one degree of freedom (i.e. rotations about the out-of-plane axis). To model the different connections, five reference points simulating the

317 joint points were first created at the theoretical position of the different joints (base, eave and apex connections), defined as the intersections of the centrelines of adjoining members. Then, each of the end faces of the column and rafter members were kinematically constrained to new reference points located at a distance of $1 \mathrm{~mm}$ from the position of the joint reference points, as illustrated in Figure 3.

321 The reference points corresponding to the bottom faces of the columns were connected to the ground reference points through $H I N G E$ type connector elements constraining rotations about the out-of-plane 
axes following a user-defined moment-rotation curve, while the reference points from the upper faces of the columns were connected to the eaves joint reference points through rigid BEAM type connector elements. The reference points of the bottom faces of the rafters were linked to the eave joint reference points by means of UJOINT type connector elements, as shown in Figure 3, which constrained rotations about the out-of-plane axis by user-defined moment-rotation curves while assigning a rigid behaviour to the remaining degrees of freedom. Finally, the apex connections were modelled by a combination of a rigid $B E A M$ type connector element (between the reference points corresponding to the upper end face of the left rafter and the apex joint reference points) and a UJOINT type connector element (between the apex joint reference points and the reference points corresponding to the upper end face of the right rafter) constraining the out-of-plane axis rotations. Appropriate bi-linear connector behaviour with the corresponding $\mathrm{K}_{1}, \mathrm{~K}_{2}, \mathrm{M}_{1}$ and $\mathrm{M}_{2}$ parameters, as defined in Figure 2, were assigned to each HINGE and UJOINT connectors (i.e. user-defined moment-rotation curves).

The out-of-plane displacement of the points corresponding to the connections of the portal frames with the longitudinal purlins and longitudinal bracings was restrained in the FE models, which corresponded to the apex and eaves joint points, the mid-height sections of the columns and the midlength sections of the rafters, as indicated in Figure 3. Initial geometric imperfections were introduced following different approaches: while the global out-of-plumb imperfections were defined by directly modifying the position of the relevant finite element nodes, member and local imperfections were introduced from prior linear buckling analyses. In all cases, appropriate imperfection amplitudes were assigned, as indicated in Sections 2.1.1 and 4.1.1 for nominal frames and structural analysis models, respectively.

Material properties were assigned through nonlinear true stress $v s$ true plastic strain relationships calculated from the material model given in $[10,11,20]$ with the appropriate material parameters for each case, as discussed in Section 2.1.3. Additionally, residual stresses were introduced in the finite element models as initial stresses using the *INITIAL CONDITIONS, TYPE-STRESS option in ABAQUS [38], with the stress pattern and magnitude adopted from the model proposed in [37] for cold-formed rectangular hollow sections. Gravity loads were applied at the upper faces of the rafters as TRVEC surface traction loads with the appropriate downwards direction and finally, the geometrically 
and materially nonlinear analyses were performed using the Static Riks method until the collapse of the

352 frames was reached. Due to the extensive computational effort required for the finite element

353 simulations, to minimise the computing time while ensuring accurate solutions, a mesh convergence 354 study was performed prior to running the simulations for two of the frames investigated, Frames 1 and

355 2. The mesh convergence study indicated that a mesh size of approximately $25 \mathrm{~mm} \times 25 \mathrm{~mm}$, with 356 around 20,000 elements, provided the most suitable compromise between computational cost and accuracy of the results.

\subsection{VALIDATION OF FINITE ELEMENT MODELS}

359 The developed finite element model was validated against the tests conducted by Arrayago et al. [30,31]

360 on austenitic single-span, single-storey stainless steel frames with flat roofs and cold-formed 361 rectangular hollow sections. Although this Section only describes the key aspects of the experimental programme, more detailed information can be found in [30,31]. The frames tested were $2 \mathrm{~m}$ high and spanned $4 \mathrm{~m}$, and were subjected to vertical and horizontal loading conditions: frames were first loaded with two vertical point loads at the rafters, and an imposed displacement was subsequently applied at the support bases while maintaining the vertical loads constant at the second loading step. Thus, the developed ABAQUS script was slightly modified to replicate the geometry and loading conditions adopted in the tests, although the main considerations discussed in the previous Section were still valid. The material properties defined in the finite element model were those obtained from tensile coupon tests and reported in [30,31]. The influence of residual stresses was implicitly included in the validation models through the material properties adopted, since the stress $v s$ strain curves were obtained from tensile tests. According to [41,42], coupons curve longitudinally when cut from cold-formed tubes as bending residual stresses are released, but return to their original straight shape when gripped and loaded in a tensile testing machine. Thus, it can be assumed that during this straightening process the bending residual stresses are re-introduced into the coupons and consequently, they do not need to be explicitly incorporated into the FE models. Likewise, global sway imperfections with the measured amplitudes were introduced in the models, combined with the reference amplitudes of L/1000 for initial member imperfections [11], since no information was available on the amplitude of these imperfections. 
The welded rafter-to-column connections in the experimental specimens were stiffened using welded steel plates, and hence were modelled as rigid knee connections by assigning high initial stiffness values $\mathrm{K}_{1}$ to the bi-linear models described in Section 2.1.2. Similarly, the rotational stiffness values measured from experimental results and reported in [30,31] were assigned to the base connections. Following the experimental set-up, the out-of-plane displacement of the loading sections and the right knee connections was restrained, as was the horizontal in-plane displacement of the reference point at the right rafter-to-column connection joint. Vertical loads were applied as point loads at the indicated locations [30,31] and the horizontal loading was introduced by imposing a prescribed displacement at the column supports. Finite element analyses were performed in two steps, following the experimental approach: for the first step the Static General method was employed to solve the geometrically and materially nonlinear analyses, while for the second horizontal loading step the Static Riks method was adopted.

The comparison between the experimental and numerical vertical load-deflection and horizontal load-displacement curves is presented in Figure 4 for the four specimens reported in [30,31], while Table 5 reports the numerical-to-experimental load ratios for the vertical and horizontal loading steps $\left(\mathrm{F}_{\mathrm{v}, \mathrm{FE}} / \mathrm{F}_{\mathrm{v}, \exp }\right.$ and $\left.\mathrm{F}_{\mathrm{h}, \mathrm{FE}} / \mathrm{F}_{\mathrm{h}, \text { exp }}\right)$, as well as for the vertical deflection and horizontal displacement ratios $\left(\mathrm{d}_{\mathrm{v}, \mathrm{FE}} / \mathrm{d}_{\mathrm{v}, \exp }\right.$ and $\left.\mathrm{d}_{\mathrm{h}, \mathrm{FE}} / \mathrm{d}_{\mathrm{h}, \text { exp }}\right)$. The calculated mean ratios and corresponding coefficients of variation $(\mathrm{COV})$, in conjunction with the load-displacement histories reported in Figure 4, indicate that the developed FE model is capable of accurately replicating the behaviour of the stainless steel frames.

\section{SYSTEM STRENGTH RELIABILITY CALIBRATIONS}

This Section presents the adopted statistical models for the random variables that mainly affect the system strength of stainless steel structures as well as the loads. The Section also provides a description of the methodology used in the reliability calibration of portal frames under gravity loads for the Eurocode and US/Australian design frameworks.

\subsection{STATISTICS OF UNCERTAIN VARIABLES}

\subsubsection{Variables affecting the resistance}

404 In the calibration of the system partial safety factors and system resistance factors for stainless steel 405 frames, the system strength distributions were estimated from extensive simulations that accounted for 
the variability of the different geometric and material random variables defining the frames. The statistics of the random variables, including geometric properties, imperfections, residual stresses and connection stiffness are summarized in Table 6 , while the variability models for the material parameters are reported in Table 7 for the three stainless steel families investigated.

The statistical characteristics of the random variables defining the cross-section geometry $(\mathrm{H}, \mathrm{B}$ and

$411 \mathrm{t})$, member $\left(\mathrm{e}_{0}\right)$ and local $\left(\gamma_{2}\right)$ imperfections, and the amplification factor $\mathrm{Y}$ for residual stress distributions in stainless steel RHS specimens adopted in this study were extracted from [43], in which extensive databases on stainless steel structural members were collated and analysed, and suitable probabilistic models were proposed. Note that the residual stress pattern has been assumed to be deterministic in this study, but assigned a random magnitude by applying a random amplification factor $\mathrm{Y}$ to the stress distribution values defined in the model proposed in [37]. Although measurements on stainless steel frame imperfections exist [30,31], they are very limited and insufficient to estimate the stochastic variability of the out-of-plumbness $\phi$. However, since the fabrication workshops for stainless steel structures are generally specialized and high-end, it can be assumed that the distributions provided for frame imperfection amplitudes in cold-formed carbon steel frames represent an upper bound for stainless steel structural frames. From a significantly broader database of measurements, a normal outof-plumb angle distribution is proposed in [9] with a mean and a standard deviation of zero and 1/610, respectively, to characterize frame imperfection uncertainties in carbon steel frames (see Table 6). Similarly, without available measurements to characterize the variability of the parameters defining the behaviour of stainless steel stiffened welded connections, the models accounting for the uncertainties related to the $K_{1}, K_{2}, M_{1}$ and $M_{2}$ parameters (as discussed in Section 2.1.2) were chosen based on the information available in the literature for steel connections. Following the assumptions made in [9] to characterize the variability of cold-formed joints, this study also assumes that the means of the $\mathrm{K}_{1}, \mathrm{~K}_{2}$, $\mathrm{M}_{1}$ and $\mathrm{M}_{2}$ parameters are equal to their nominal values and that they can be modelled by log-normal distributions, as reported in Table 6 . The coefficients of variation adopted in the present study have also been based on the values assumed in [9], with a COV of 0.30 for the initial stiffness $\mathrm{K}_{1}$, which shows the largest uncertainty relative to the other parameters defining the behaviour of connections, and COVs of $0.15,0.10$ and 0.15 for $\mathrm{K}_{2}, \mathrm{M}_{1}$ and $\mathrm{M}_{2}$, respectively. 
The statistical characterization of the material parameters defining the stress-strain behaviour of stainless steel alloys is summarized in Table 7, based on the results reported in [43]. Note that the overstrength ratios (mean-to-nominal ratios) for the enhanced yield stress $\mathrm{f}_{\mathrm{y} \text {,enh }}$ and ultimate tensile strength $\mathrm{f}_{\mathrm{u}}$ reported in Table 7 refer to the nominal values corresponding to the European structural and material standards $[2,34,35]$, which implies that the equivalent overstrength ratios relative to the ASCE 8 [20] or AS/NZS 4673 [22] specifications would be higher owing to the lower nominal values codified in these standards (as per the values reported in Table 2 against those given in Table 3 and Table 4). Although this study uses the European yield stress $\mathrm{f}_{\mathrm{y}}$ and ultimate tensile strength $\mathrm{f}_{\mathrm{u}}$ as reference values to model the actual $f_{y}$ and $f_{u}$ values, it would have been possible to follow alternative approaches based on the ASCE 8 [20] or AS/NZS 4673 [22] nominal values and associated overstrength ratios.

The analysis presented in this paper assumed deterministic overall frame properties (frame span, column height and height at apex), while perfect correlation between all members for the random crosssectional properties (height $\mathrm{H}$, width B and thickness t), material properties (Young's modulus $\mathrm{E}$, yield stress $\mathrm{f}_{\mathrm{y}}$, ultimate tensile strength $\mathrm{f}_{\mathrm{u}}$, ultimate strain $\varepsilon_{\mathrm{u}}$ and strain-hardening exponents $n$ and $m$ ) and residual stress magnitudes were adopted. The assumption of perfect correlation has been shown to be usually conservative for reliability evaluations [6]. Additionally, member and local imperfections and the parameters governing the behaviour of connections $\left(\mathrm{K}_{1}, \mathrm{~K}_{2}, \mathrm{M}_{1}\right.$ and $\left.\mathrm{M}_{2}\right)$ were defined as random variables with no correlation.

\subsubsection{Model uncertainty}

One of the most important stochastic variables in the calibration of safety or resistance factors for direct analysis is model uncertainty. Model uncertainty arises from assumptions and approximations made in determining the strength of a structure using advanced FE models and might have a substantial influence on the computed resistances [44]. Thus, it is important that it is considered in reliability analyses. According to prEN 1993-1-14, Annex A [11], the model uncertainty for advanced analysis $\gamma_{\mathrm{FE}}$ or $\theta$ can be estimated by comparing experimental data to the results predicted from advanced analysis, provided that the experimental specimen is similar in the failure mode and in the controlling parameters (relative 
cases in which experimental results are available, the model factor may be calculated based on statistical evaluations according to the rules given in the EN 1990 Annex D [45], as per clause (4) in prEN 19931-14, Annex A [11]. However, for the case of complex structural systems such as frames, the availability of experimental results to be adopted as benchmarks are considerably scarce, and in such cases more generic statistical characterizations found in the literature need to be adopted for model uncertainties. The approaches adopted by different authors to account for model uncertainty include unbiased normal distributions with a COV of 0.05 [8] and log-normal distributions with a mean and COV of 1.0 and 0.05 , respectively $[46,47]$.

The finite element model developed for the present study was validated against four tests on stainless steel frames, as described in Section 3.2, with a mean and COV of the FE-to-experimental results equal to 1.02 and 0.024 , respectively (see Table 5). Although these results indicate that the FE models were capable of replicating the behaviour of stainless steel frame tests, there was insufficient information to derive a probabilistic characterization of the model uncertainty. Thus, the model uncertainty statistics adopted in this study for the reliability calibrations were assumed to be log-normally distributed with mean and COV of 1.0 and $0.05[46,47]$. In order to incorporate the model uncertainty in the statistics of the frame strength, simulation results were combined with the model uncertainty by multiplying each simulated system strength by a randomly generated value of model uncertainty factor [8] based on a log-normal distribution with mean of 1.0 and a COV of 0.05 .

\subsubsection{Load statistics}

The statistical distributions adopted in the literature for gravity loads (i.e. permanent (dead) loads and imposed (live) loads) in the different design frameworks tend to be consistent in terms of the distribution types adopted, although have considerably different mean-to-nominal and COV values, especially for imposed loads. This can be explained by the limited amount of available imposed load surveys and the considerably different nominal imposed load values prescribed for equivalent floor uses in international standards EN 1991-1-1 [48], ASCE 7 [49] and AS/NZS 1170.1 [50]. In general, the permanent loads are assumed to be normally distributed with mean values equal or very close to the characteristic or nominal value of the action and small coefficients of variation for the three design frameworks considered [46,47,51], as per the values reported in Table 8. Imposed live loads are the most uncertain 
of the stochastic variables, and although different studies and authors consistently adopt Extreme Type

490 I (Gumbel) statistical distributions, a variety of mean-to-nominal and COV values can be found in the

491 literature. For the US framework, most studies have adopted a mean-to-nominal value equal to 1.0 with

492 a COV of 0.25 for imposed loads [5,6,8,51], while for the Eurocode framework the literature includes

493 mean-to-nominal values ranging between $0.40,0.60$ and 0.70 , with coefficients of variations between

$494 \quad 0.2$ and $0.6[46,52,53]$.

495 The approach followed in this study to define the mean-to-nominal and COV values for imposed

496 loads in the different design frameworks was to use the nominal values provided in each relevant load

497 standard (i.e. EN 1991-1-1 [48], ASCE 7 [49] and AS/NZS 1170.1 [50] for the Eurocode, US and

498 Australian frameworks, respectively). Following the recommendations in [48,49,50], the nominal load

499 values were multiplied by reduction factors that account for different tributary areas, which are also

500 slightly different in the three loading standards. For each category of floor use defined in EN 1991-1-1

501 [48] (including residential activities, office areas, restaurants, theatres, museums, gymnastic rooms and

502 shopping areas) the reduced nominal imposed loads were calculated for the three load standards and for

503 tributary areas ranging between $50-200 \mathrm{~m}^{2}$, and averaged reduced nominal loads were calculated for

504 this range of areas for each standard to produce imposed loads $q_{k, i, a v}(E N), q_{n, i, a v}($ ASCE) and

$505 \mathrm{q}_{\mathrm{n}, \mathrm{i}, \mathrm{av}}($ AS/NZS), where $i$ represents the different floor use categories. Loads for the US framework were

506 normalized for each category by the corresponding reduced nominal loads according to the Eurocode

507 and Australian frameworks, $\mathrm{q}_{\mathrm{n}, \mathrm{i}, \mathrm{av}}\left(\right.$ ASCE) $/ \mathrm{q}_{\mathrm{k}, \mathrm{i}, \mathrm{av}}(\mathrm{EN})$ and $\mathrm{q}_{\mathrm{n}, \mathrm{i}, \mathrm{av}}\left(\right.$ ASCE) $/ \mathrm{q}_{\mathrm{k}, \mathrm{i}, \mathrm{av}}(\mathrm{AS} / \mathrm{NZS})$, and finally

508 averaged load ratios were calculated from the different floor use categories.

509 Results indicated that, on average, imposed live loads corresponding to the US framework represent

$51080 \%$ of the loads in the Eurocode framework, while similar values were obtained for the US and the

511 Australian design frameworks. From these relationships, the mean-to-nominal values adopted for the

512 reliability calibrations derived in this study corresponded to 1.0 for the US and the Australian design

513 frameworks and 0.80 for the Eurocode framework; i.e. EN 1991-1-1 [48], the standard with the most

514 conservative (highest) nominal loads on average. For the three cases, the same coefficient of variation

515 of 0.25 and an Extreme Type I distribution were adopted [51]. The adoption of a mean-to-nominal 
imposed load equal to 0.80 for the Eurocode framework is more conservative than some of the values

517 reported in the literature, which results in lower values of estimated probabilities of failure $[46,52,53]$.

518 The information about the final statistical distributions adopted for imposed live loads in the three

519 design frameworks is summarized in Table 8.

\subsection{SYSTEM RELIABILITY ANALYSIS METHOD}

521

522

523

524

Eurocode framework:

US framework:

Australian framework:

$$
1.35 \mathrm{G}_{\mathrm{k}}+1.50 \mathrm{Q}_{\mathrm{k}}
$$$$
1.20 D_{n}+1.60 L_{n}
$$$$
1.20 G_{n}+1.50 Q_{n}
$$

Eq. 3

Eq. 4

Eq. 5

The limit state functions are reformulated to account for permanent loads and imposed loads as per $\mathrm{g}=$ $\mathrm{R}-\mathrm{G}-\mathrm{Q}$ or $\mathrm{g}^{*}=\mathrm{R}-\mathrm{D}-\mathrm{L}$, and the probability of failure of each structural system can be computed following the steps listed below. Note that only a summary of the procedure is provided in this paper, 
since the adopted methodology has been extensively reported in the literature $[5,6,8,9]$. However, the

542 DDM methodology has only been applied to the Australian and US design frameworks, and thus the

543

544

545

Eurocode framework:

US framework:

Australian framework: per frame. details for its extension to the Eurocode framework are highlighted:

(1) Determine the probabilistic models (distribution type and parameters) for the system resistance $\mathrm{R}$ under gravity loads accounting for all the relevant uncertainties. For this, extensive simulations are carried out using the finite element model described in Section 3 and the statistics of the random variables reported in Section 4.1. By adopting the Latin-Hypercube sampling (LHS) technique, the number of required simulations to determine the probabilistic models for $\mathrm{R}$ is reduced to 200 cases

(2) Re-write the LRFD design equations (Eq. 1 and Eq. 2) for the gravity load combinations considered in the Eurocode, US and Australian design frameworks as per Eq. 6 to Eq. 8, in which $\gamma_{M, S}$ is the system safety factor and $\phi_{\mathrm{S}}$ is the system resistance factor.

(3) For a range of $\gamma_{M, s}$ and $\phi_{s}$ values, define the relationship between the nominal resistance $R_{n}$ and the nominal permanent and imposed gravity loads through the Load Scale Method and the LRFD design equations [12]. The nominal loads $G_{k}, Q_{k}, D_{n}, L_{n}, G_{n}$ and $Q_{n}$ can be re-written in terms of the characteristic or nominal resistances $R_{k}$ and $R_{n}$ as per in Eq. 9 to Eq. 11, where $\alpha$ is the imposed-to-permanent (live-to-dead) load ratio, $\alpha=Q_{k} / G_{k}, \alpha=L_{n} / D_{n}$ or $\alpha=Q_{n} / G_{n}$.

Eurocode framework:

US framework:

Australian framework:

$$
\frac{\mathrm{R}_{\mathrm{k}}}{\gamma_{\mathrm{M}, \mathrm{s}}}=1.35 \mathrm{G}_{\mathrm{k}}+1.50 \mathrm{Q}_{\mathrm{k}}
$$

Eq. 6

Eq. 8

(4) Re-define the probabilistic models for permanent and imposed loads from the relationships defined in Step (3) and the models available in the literature and reported in Table 8. 
(5) Compute the probability of failure $\mathrm{P}_{\mathrm{f}}$ using the First-Order Reliability Method (FORM) [55]. The reliability index $\beta$ is commonly adopted as a measurement of the probability of failure, and can be calculated for each value of $\gamma_{\mathrm{M}, \mathrm{s}}$ and $\phi_{\mathrm{s}}$ considered. The reliability index is related to the

Using the reliability analysis method described above, system reliability indices $\beta$ can be computed and the relationships between system reliability indices $\beta$ and system safety factors $\gamma_{\mathrm{M}, \mathrm{S}}$ or system resistance factors $\phi_{\mathrm{S}}$ can be established for a range of imposed-to-permanent (live-to-dead) load ratios $\alpha$. This is addressed in the following section for the six stainless steel frames investigated in this paper.

\section{RELIABILITY CALIBRATION RESULTS FOR THE ULTIMATE LIMIT STATE}

This Section presents the results for the reliability calibration of stainless steel frames subjected to gravity loads. The system strength distributions are provided first for the six portal frames, and the reliability calibration results corresponding to the Eurocode, US and Australian frameworks are subsequently presented and compared.

\subsection{SYSTEM STRENGTH OF STAINLESS STEEL FRAMES UNDER GRAVITY LOADS}

System strength distributions for stainless steel frames under gravity loads were obtained from numerical simulations accounting for the variability of the random variables defined in Section 4.1 and using the FE models described in Section 3. The ultimate loads of the frames were determined from the load-vertical deflection curves obtained from the finite element simulations for the apex joint reference points: for those frames showing load-deflection curves with a clear peak point, this peak load was adopted as the ultimate load; on the contrary, where no clear peak point existed the load at which the stiffness of the curve fell below a value of $5 \%$ of the initial stiffness was defined as the ultimate load $[9,56]$. It is worth noting that the ultimate loads of frames showing sway failure modes (Frames 2, 4 and 6) were typically obtained as the peak loads, while for those frames reaching advanced stages of yielding (Frames 1, 3 and 5) the stiffness limit criteria governed. The histograms for the system strengths are reported in Figure 5 for the six fames analysed, and suggest the system strengths of frames under gravity loads can be accurately fitted by log-normal distributions, consistent with those obtained 
in other studies $[6,8,9,13]$. The fit of the log-normal distributions was carried out by means of the

590 Statistics and Machine Learning Toolbox in MATLAB [57], based on the maximum likelihood method.

591 The Anderson-Darling (AD) goodness-of-fit tests were used to evaluate the resulting distributions at

592 the 5\% significance level [58]. It is important to highlight that the obtained system strength distributions

593 are valid for the analysis of the structural reliability of stainless steel frames regardless of the design

594 framework considered, since they are based on the geometric, material, imperfection and connection properties defined from probabilistic models established from measurements on real stainless steel structures and members. The differences between the reliability calibration results presented in the next sections result from the different nominal system resistances obtained for each design framework, as well as from the different load combinations and load statistics assumed for the three frameworks.

Mean values of the system strengths $\mathrm{R}_{\mathrm{m}}$ and corresponding COVs are summarized in Table 9, together with the nominal frame resistances for the three design frameworks investigated in this study $R_{k, E N}, R_{n, U S}$ and $R_{n, A U}$, which were determined from finite element simulations following Sections 2.1 and 3, and the corresponding mean-to-nominal resistance ratios $\mathrm{R}_{\mathrm{m}} / \mathrm{R}_{\mathrm{n}, \mathrm{i}}$. The results in Table 9 show that the nominal resistances are very similar regardless the adopted design framework for Frames 5 and 6, since the nominal material properties are similar for ferritic stainless steels in the Eurocode and Australian/US frameworks. However, for the remaining frames representing austenitic (Frames 1 and 2) and duplex (Frames 3 and 4) stainless steels, the nominal resistances are lower for the Australian/US frameworks than for the Eurocode framework owing to the significantly lower nominal material properties specified for the considered EN 1.4301/ASTM 304 and EN 1.4462/ASTM 2205 grades, as per the yield stress values reported in Table 2, Table 3 and Table 4. Analysing the mean-to-nominal resistance ratios reported in Table 9, it is evident that austenitic and ferritic stainless steel frames failing in non-sway modes (Frames 1 and 5) present a higher strength reserve (i.e. higher mean-to-nominal resistance ratios) than the frames failing in sway modes (Frames 2 and 6) due to the partial load redistribution occurring in the non-sway frames and the overstrength ratios that these stainless steel families present (see Table 7). On the contrary, the $R_{m} / R_{n, i}$ strength reserve in the case of the non-sway duplex Frame 3 is lower than for the other stainless steel non-sway frames (Frames 1 and 5) due to the limited redistribution capacity of this frame, as discussed in Section 2.2, and the lower overstrength 
617 ratios exhibited by duplex stainless steels. Consequently, the $\mathrm{R}_{\mathrm{m}} / \mathrm{R}_{\mathrm{n}, \mathrm{i}}$ ratios observed for the duplex

618 stainless steel Frame 3 and Frame 4 are equal within each design framework. The results also indicate

619 that the uncertainty (COV) of the system resistance of all frames is around 0.09-0.12. Note that the

620 higher mean-to-nominal resistance ratios observed for Frames 1 to 4 in the US and Australian

621 frameworks are caused by the lower nominal material properties provided for austenitic and duplex

622 grades in the ASCE 8 [20] and AS/NZS 4673 [22] specifications.

\section{5.2. RELIABILITY CALIBRATION RESULTS FOR FRAMES UNDER GRAVITY LOADS}

624 Following the procedure described in Section 4.2, the results of the reliability calibrations for stainless

625 steel portal frames under gravity loads are presented in this Section for the three design frameworks.

626 These results are based on the probabilistic models for system resistance presented in Section 5.1 and

627 the nominal system resistances calculated according to the relevant provisions for each design 628 framework, as discussed in Section 2.

629 Derived $\beta-\gamma_{M, S}$ curves for the Eurocode design framework are presented in Figure 6 for the six 630 stainless steel portal frames investigated in this paper, considering different imposed-to-permanent load ratios $Q_{k} / G_{k}$. While the imposed-to-permanent load ratio typically ranges from 0.5 to 4.0 [59], the common load ratio for hollow section steel structures is $Q_{k} / G_{k}=2.0$ [8]. Consequently, this study assumed imposed-to-permanent load ratios close to 2.0, between 1.0 and 3.0. In the figure, the target reliability index $\beta_{0}=3.8$ corresponding to the minimum value recommended in EN 1990 [45] for CC2 consequence class structures for a 50-year reference period for the ultimate limit state is also indicated, which is commonly considered in reliability analyses carried out in the Eurocode framework. The results shown in Figure 6 demonstrate that the reliability index $\beta$ increases with increasing system safety factor $\gamma_{M, S}$, as would be expected, while for a given value of system safety factor $\gamma_{M, S}$ the reliability index $\beta$ decreases as the imposed-to-permanent load ratio $Q_{k} / G_{k}$ increases. This is because imposed loads show higher variability than permanent loads (see statistical parameters in Table 8) and thus not only is the reliability of a structure dependent on the imposed-to-permanent load ratio, but the reliability reduces when the variable loads become dominant. 

frames for the US and Australian design frameworks, respectively, for the same imposed-to-permanent

645 load ratios $L_{n} / D_{n}$ or $Q_{n} / G_{n}$ as those considered for the Eurocode framework. The target reliability 646 index $\beta_{0}=2.5$ is included in the figures for the US and Australian design frameworks since this target 647 reliability index has been historically adopted for steel structures in the US and Australian frameworks $648[60,61]$. The curves shown in Figure 7 and Figure 8 decrease with increasing system resistance factor $649 \phi_{s}$, which is the opposite trend to that observed in Figure 6 for the Eurocode design framework, because the resistance factor is equivalent to the inverse of the safety factor $\gamma_{\mathrm{M}, \mathrm{s}}$. However, it can be seen that for a given value of resistance factor $\phi_{s}$ the reliability index decreases with increasing values of $L_{n} / D_{n}$ or $Q_{n} / G_{n}$, as also found for the Eurocode framework. Comparisons between the $\beta-\gamma_{M, s}$ and the $\beta-\phi_{\mathrm{s}}$ curves derived for the different design frameworks indicate that the values of the derived reliability indices are generally lower in Figure 7 and Figure 8 than for the Eurocode design framework in Figure 6 for equivalent design situations, suggesting that the Eurocode design framework may be a more conservative design approach than the US and Australian frameworks. This finding is further investigated in the following Section.

\subsection{COMPARISON, DISCUSSION AND RECOMMENDATIONS}

This Section presents a comparison between the reliability calibrations corresponding to the three design frameworks investigated in this paper and a discussion of the reliability index $\beta$ values obtained for the different frames. Subsequently, recommendations for the system safety factor $\gamma_{\mathrm{M}, \mathrm{s}}$ and resistance factors $\phi_{\mathrm{s}}$ to be adopted for the analysis-based design of stainless steel frames under gravity loads are provided.

Figure 9 compares the derived $\beta-\gamma_{M, S}$ curves corresponding to the Eurocode framework for the six stainless steel frames analysed in this paper with the equivalent $\beta-1 / \phi_{\mathrm{s}}$ curves for the US and Australian frameworks. In the figure, each frame is represented by a different colour, while each design framework is plotted with a different line style. Since the reliability index $\beta$ depends on the imposedto-permanent load ratio $Q_{k} / G_{k}$, it is not possible to achieve a uniform level of reliability for different $Q_{k} / G_{k}$ ratios with a single value of $\gamma_{M, S}$ or $\phi_{s}$. Equally, it would not be practical for engineering practice 
to have different safety factors for different load ratios. Thus, the results presented in Figure 9 are for the imposed-to-permanent load ratio of $Q_{k} / G_{k}=2$ (or $L_{n} / D_{n}=2, Q_{n} / G_{n}=2$ ), which corresponds to a typical load ratio for hollow section steel structures [8]. Four different target reliability indices $\beta_{0}$ have been highlighted in the Figure: 3.8, 3.3, 3.0 and 2.5. The first two values (3.8 and 3.3) correspond to the minimum values recommended in EN 1990 [45] for consequence classes CC2 and CC1, while values 3.0 and 2.5 refer to the target reliability indices traditionally adopted in the US and Australian frameworks $[60,61]$. The probabilities of failure corresponding to these target reliability indices are $7.23 \cdot 10^{-05}, 4.83 \cdot 10^{-04}, 1.35 \cdot 10^{-03}$ and $6.21 \cdot 10^{-03}$, respectively.

From the $\beta-\gamma_{\mathrm{M}, \mathrm{s}}$ and $\beta-1 / \phi_{\mathrm{s}}$ curves reported in Figure 9 it can be appreciated that the Eurocode framework is the one providing the highest reliability indices owing to the lower 0.80 mean-to-nominal values adopted by this framework for the imposed variable load (see Table 8), which means that the nominal imposed loads specified in EN 1991-1-1 [48] are in general more conservative than for the equivalent load standards ASCE 7 [49] and AS/NZS 1170.1 [50]. The relatively high reliability indices for the Eurocode are followed by the US framework, and the lowest indices are observed for the Australian framework. Given that the US and Australian frameworks adopt the same mean-to-nominal values for the imposed loads (as shown in Table 8), differences between the US and Australian $\beta-1 / \phi_{\mathrm{s}}$ curves can be explained by the slightly more conservative load combination adopted by the ASCE 7 [49] Specification over the AS/NZS 1170.0 [54] standard, as indicated by the load factors affecting the imposed loads in Eq. 4 and Eq. 5. Despite the differences observed between the three design frameworks, the relative reliability indices obtained for the six stainless steel frames are similar within each of the design frameworks, and are consistent with the mean-to-nominal resistance ratios $R_{m} / R_{n, i}$ reported in Table 9. The lowest reliability levels are observed in all frameworks for the frames showing sway failure modes (Frames 2, 4 and 6), while the $\beta-\gamma_{\mathrm{M}, \mathrm{s}}$ curves for frames showing nonsway failure modes (Frames 1, 3 and 5) are typically higher. However, the high overstrength ratios (mean-to-nominal yield stress ratios) for austenitic and duplex alloys result in higher reliability indices for Frames 1, 2, 4 and 5 in the US and Australian frameworks. The adoption of more accurate and 
consistent nominal yield stress values across the different design frameworks would lead to more uniform reliabilities for the different stainless steel families.

There is a wide variation of target reliability indices adopted by the different standards, which can be attributed to historical reasons. When building design codes switched from allowable stress design to the LRFD format in the late 1980's, different research works were carried out to determine the level of safety embodied in the existing building codes for different construction materials, components (beams, columns, joints), loads and types of buildings [62]. Based on the reliability indices derived, safety factors were calibrated for the load and resistance factored design (LRFD), aiming to obtain reliability levels that differed as little as possible from the historically evolved and accepted levels (which would result in a minimum change in design practice) and to provide as small a scatter as possible with regard to the target value of $\beta_{0}$. The variability observed between the various studies was large, and so was the scatter between various materials, types of components and types of loads. For example, the values of $\beta$ ranged between 2.2 and 6.1 , with an average value of 3.8 , in the study conducted by Vrouwenvelder and Siemes [63] for buildings in the Netherlands, while an average value of 3.0 was obtained by Galambos et al. [64] for the US. The first drafts of the Eurocodes adopted the commonly accepted value of $\beta_{0}=3.8$ for 50 years as an appropriate target value for $\mathrm{CC} 2$ consequence class structures [62], while the significantly lower value of $\beta_{0}=3.0$ was chosen in the ASCE 7 [49] Specification for Risk Category II structures to provide not only protection against structural failure, but also against property and economic damage for small events; however, the Commentary of the Standard states that at the present time there is no documentation justifying the reliability intended. The probability of failure associated with $\beta_{0}=3.8$ is about 20 times lower than that for $\beta_{0}=3.0$. However, it should be noticed that these target reliability indices are intended for the design of new structures, and not for the assessment of existing structures; strengthening existing structures is more costly and such structures will typically have service lives shorter than 50 years, and thus lower reliability targets can be accepted [62].

Table 10 summarizes the required system safety factors $\gamma_{M, S}$ and system resistance factors $\phi_{S}$ derived for the different design frameworks and the four target reliability indices considered in the 
analysis, $\beta_{0}=3.8,3.3,3.0$ and 2.5 , corresponding to the imposed-to-permanent load ratio of $Q_{k} / G_{k}=$

724 2. For comparison purposes, the inverse values of the reported system safety factors $1 / \gamma_{M, s}$ and system

725

726

727 resistance factors $1 / \phi_{\mathrm{s}}$ are also included as comparable measures of equivalent system resistance factors $\phi_{\mathrm{s}}$ and system safety factors $\gamma_{\mathrm{M}, \mathrm{s}}$, respectively. It is worth noting that some of the system safety factors $\gamma_{\mathrm{M}, \mathrm{S}}$ reported in Table 10 for the Eurocode framework show values below unity, particularly for the lowest target reliability indices considered. This means that the resistance reserve $R_{m} / R_{k, E N}$ existing in the investigated stainless steel frames is sufficient to meet some of the lowest reliability requirements without the need to apply additional resistance reduction through the $\gamma_{\mathrm{M}, \mathrm{S}}$ factor, which can be attributed to the high yield overstrength ratios generally obtained for stainless steels (see values reported in Table 7), or equivalently, to the excessively low nominal yield stress values considered in the standards. Likewise, and for similar reasons, some of the system resistance factors $\phi_{\mathrm{s}}$ shown in Table 10 are above unity for the lowest target reliability indices analysed for the US and Australian frameworks. Note that the results reported in Table 10 were calculated accounting for model uncertainties as described in Section 4.1.2. Equivalent analyses without considering model uncertainty produced uncertainty (COV) of the system resistance of all frames in the range from 0.07 to 0.10 ; lower that the range $(0.09-0.12)$ obtained in Section 5.1 when model uncertainly was considered. The lower uncertainty of the system resistance resulted in an average $2.5 \%$ change of the system safety factors and system resistance factors reported in Table 10.

The required system safety factors $\gamma_{\mathrm{M}, \mathrm{S}}$ reported in Table 10 for the target reliability index of $\beta_{0}=$ 3.8 prescribed in EN 1990 [45] range between 1.10 and 1.17, with the lowest values aligned with nonsway frames (Frames 1, 3 and 5). Similarly, to meet a target reliability index of $\beta_{0}=2.5-3.0$ for the US and Australian frameworks, system resistance factors $\phi_{\mathrm{s}}$ ranging between $0.88-1.02$ and $0.85-0.97$ would be required, respectively. On average, to achieve a $\beta_{0}=3.8$ value for stainless steel frames under gravity loads a $\gamma_{\mathrm{M}, \mathrm{S}}$ of 1.15 may be adopted for the Eurocode framework, while $\phi_{\mathrm{s}}$ factors of 0.95 and 0.90 are recommended for the US and Australian frameworks, respectively. Note that the inverse of the system safety factor proposed for the Eurocode framework $1 / 1.15=0.87$ is not far from the resistance factors 0.90 and 0.95 recommended for the US and Australian frameworks. It should be also noted that 
the recommended $\gamma_{\mathrm{M}, \mathrm{s}}$ and $\phi_{\mathrm{s}}$ factors are to be used only when designing stainless steel frames under gravity loads. Since calibrations for other load combinations including wind loads typically show lower reliability indices than for structures in which gravity loads govern [65], independent calibrations are necessary for stainless steel frames under combined gravity and wind loads for the recommendation of suitable $\gamma_{\mathrm{M}, \mathrm{s}}$ and $\phi_{\mathrm{s}}$ factors.

\section{CONCLUSIONS}

System-based design approaches represent a change in the paradigm of structural design with a strong potential not only for the design of lighter and more efficient new structures, but also for the reassessment and reinforcement of existing structures. Provisions for analysis-by-design approaches have been incorporated in several international design codes for steel structures $[3,4,10]$, but no specific reliability requirements or acceptable target reliability indices are provided for structural systems. Although system-based design recommendations have been proposed for different types of steel structures, including hot-rolled and cold-formed frames, as well as rack and scaffolding structures, in the form of the Direct Design Method (DDM), the Method has not yet been extended to stainless steel structures, and there is no developed system reliability framework for this material. This paper presents the first step in the extension of the DDM to stainless steel structures, presenting system reliability analyses for stainless steel portal frames under gravity loads using advanced nonlinear numerical simulations.

The system reliability calibration is based on six typical single-bay, single-storey stainless steel portal frames, which cover different failure modes and the three most common stainless steel grades (austenitic EN 1.4301/ASTM 304, duplex EN 1.4462/ASTM 2205 and ferritic EN 1.4003/ASTM UNS S40977 grades). The study was based on extensive finite element simulations that accounted for the variability of the random variables affecting the system resistance (including geometric properties, imperfections, material properties, connection behaviour and model uncertainty), from which the probabilistic characteristics of the ultimate frame strengths under gravity loads were determined. Results showed that high mean-to-nominal strength ratios exist for stainless steel frames due to the considerably low nominal material properties specified for these materials, especially for austenitic and 
ferritic grades. From the system strength probabilistic distributions, and in conjunction with First-Order Reliability Method (FORM) techniques, system safety factors $\gamma_{\mathrm{M}, \mathrm{s}}$ and system resistance factors $\phi_{\mathrm{s}}$ were derived for the direct design of stainless steel frames under gravity loads according to the European, US and Australian design frameworks, considering a range of target system reliability indices $\beta_{0}$. The results suggested that a system safety factor of $\gamma_{\mathrm{M}, \mathrm{s}}=1.15$ may be adopted for the Eurocode framework to achieve a target reliability index of $\beta_{0}=3.8$, while resistance factors of $\phi_{\mathrm{s}}=0.95$ and 0.90 are appropriate for the US and Australian frameworks, respectively, for a target index of $\beta_{0}=3.0$. These recommendations are based on the results obtained from reliability calibrations in this paper and can be of assistance to specification committees in defining suitable values for $\gamma_{\mathrm{M}, \mathrm{S}}$ and $\phi_{\mathrm{S}}$, although the choice of target reliability indices ultimately rest with these committees and will affect the safety and resistance factors. Further research to determine $\gamma_{M, s}$ and $\phi_{S}$ factors for stainless steel frames under combined gravity and wind loads is underway.

\section{ACKNOWLEDGEMENTS}

This project has received funding from the European Union's Horizon 2020 Research and Innovation Programme under the Marie Sklodowska-Curie Grant Agreement No. 842395.

\section{REFERENCES}

[1] European Committee for Standardization (CEN). prEN 1993-1-1. Eurocode 3: Design of Steel Structures - Part 1-1: General Rules and Rules for Buildings. Final Document. Brussels, Belgium, 2019. [2] European Committee for Standardization (CEN). prEN 1993-1-4. Eurocode 3: Design of Steel Structures - Part 1-4: General Rules. Supplementary Rules for Stainless Steels. Third draft. Brussels, Belgium, 2020.

[3] AS/NZS 4100 Steel Structures. Standards Australia, Sydney, Australia, 2020.

[4] American Institute of Steel Construction (ANSI/AISC). AISC 360-16. Specification for Structural Steel Buildings. Illinois, USA, 2016.

[5] Zhang H., Liu H., Ellingwood B.R. and Rasmussen K.J.R. System reliabilities of planar gravity steel frames designed by the inelastic method in AISC 360-10. Journal of Structural Engineering (ASCE) 144(3):04018011, 2018. 
804 [6] Zhang H., Shayan S., Rasmussen K.J.R. and Ellingwood B.R. System-based design of planar steel 805 frames, I: Reliability framework. Journal of Constructional Steel Research 123, 135-143, 2016.

806 [7] Zhang H., Shayan S., Rasmussen K.J.R. and Ellingwood B.R. System-based design of planar steel 807 frames, II: Reliability results and design recommendations. Journal of Constructional Steel Research $808 \quad 123,154-161,2016$.

809 [8] Liu W., Zhang H. and Rasmussen K.J.R. System reliability-based Direct Design Method for space 810 frames with cold-formed steel hollow sections. Engineering Structures 166, 79-92, 2018.

811 [9] Sena Cardoso F., Zhang H., Rasmussen K.J.R. and Yan S. Reliability calibrations for the design of 812 cold-formed steel portal frames by advanced analysis. Engineering Structures 182, 164-171, 2019.

813 [10] American Institute of Steel Construction (ANSI/AISC). AISC 370. Specification for Structural 814 Stainless Steel Buildings. Illinois, USA, 2021.

815 [11] Working Group 22 for Eurocode 3 CEN/TC 250/SC3/WG22. prEN 1993-1-14. Eurocode 3: 816 Design of steel structures - Part 1-14: Design assisted by finite element analysis. Brussels, Belgium. 817 Under development.

818 [12] Sena Cardoso F., Zhang H. and Rasmussen K.J.R. System reliability-based criteria for the design 819 of steel storage rack frames by advanced analysis: Part II - Reliability analysis and design applications. Thin-Walled Structures 141, 725-739, 2019.

821 [13] Wang C., Zhang H., Rasmussen K.J.R., Reynolds J. and Yan S. Reliability-based limit state design of support scaffolding systems. Engineering Structures 216, 110677, 2020.

823 [14] NewGeneSS, New Generation Design Methods for Stainless Steel Structures. Marie Sklodowska824 Curie Fellowship 2018, funded by the European Union's Horizon 2020 Research and Innovation 825 Programme under Grant Agreement No. 842395.

826 [15] Baddoo N.R. Stainless steel in construction: A review of research, applications, challenges and opportunities. Journal of Constructional Steel Research 64(11), 1199-1206, 2008.

828 [16] Cashell K.A. and Baddoo N.R. Ferritic stainless steels in structural applications. Thin-Walled Structures 83, 169-181, 2014.

830 [17] Afshan S., Francis P., Baddoo N.R. and Gardner L. Reliability analysis of structural stainless steel 831 design provisions. Journal of Constructional Steel Research 114, 293-304, 2015. 
832 [18] Gardner L. Stability and design of stainless steel structures - Review and outlook. Thin-Walled 833 Structures 141, 208-216, 2019.

834 [19] Walport F., Gardner L., Real E., Arrayago I. and Nethercot D.A. Effects of material nonlinearity 835 on the global analysis and stability of stainless steel frames. Journal of Constructional Steel Research $836152,173-182,2019$.

837 [20] American Society of Civil Engineers (ASCE). SEI/ASCE 8. Specification for the Design of Cold838 Formed Stainless Steel Structural Members. Virginia, USA, 2021.

839 [21] American Iron and Steel Institute (AISI). AISC S100-16. North American Specification for the 840 Design of Cold-Formed Steel Structural Members. Illinois, USA, 2016.

841 [22] AS/NZS 4673 Cold-formed stainless steel structures. Standards Australia, Sydney, Australia, 8422001.

843 [23] Henderson J.R. Design of steel portal frame buildings to Eurocode 3. SCI Publication P399. UK, 2015.

[24] Salter P.R., Malik A.S. and King C.M. Design of single-span steel portal frames to BS 59501:2000. SCI Publication P252. UK, 2004.

846 [25] Gardner L. and Nethercot D.A. Numerical modelling of stainless steel structural components - A consistent approach. Journal of Structural Engineering (ASCE) 130(10), 1586-1601, 2004.

[26] Packer J.A., Wardenier J., Kurobane Y., Dutta D. and Yeomans N. Design guide for rectangular hollow section (RHS) joints under predominantly static loading. CIDECT Design Guide No. 3. Verlag TÜV Rheinland GmbH, Köln, Germany, 1992.

[27] Wilkinson T. and Hancock G.J. Tests to examine plastic behaviour of knee joints in cold-formed RHS. Journal of Structural Engineering (ASCE) 126(3), 297-305, 2000.

[28] Mang F., Steidl G. and Bucak O. Design of welded lattice joints and moment resisting knee joints made of hollow sections. International Institute of Welding, Document XV-463-80. University of Karlsruhe, Germany, 1980.

[29] Wardenier J. Hollow section joints. Delft University Press. Delft, The Netherlands, 1982. 
859 [31] Arrayago I., González-de-León I., Real E. and Mirambell E. Tests on stainless steel frames. Part

860 II: Results and analysis. Thin-Walled Structures 157,107006, 2020.

861 [32] Arrayago I., Real E. and Gardner L. Description of stress-strain curves for stainless steel alloys. Materials and Design 87, 540-552, 2015.

863 [33] Rasmussen K.J.R. Full-range stress-strain curves for stainless steel alloys. Journal of Constructional Steel Research 59(1), 47-61, 2003.

[34] Steel Construction Institute (SCI). Design Manual for Structural Stainless Steel. Fourth Edition. UK, 2017.

866 [35] European Committee for Standardization (CEN). EN 10088-4. Stainless Steels Part 4: Technical

867 Delivery Conditions for Sheet/Plate and Strip of Corrosion Resisting Steels for Construction Purposes.

868 Brussels, Belgium, 2009.

869 [36] Rossi B., Afshan S. and Gardner L. Strength enhancements in cold-formed structural sections Part II: Predictive models. Journal of Constructional Steel Research 83, 189-196, 2013.

[37] Gardner L. and Cruise R.B. Modeling of residual stresses in structural stainless steel sections. Journal of Structural Engineering (ASCE) 135(1), 42-53, 2009.

873 [38] ABAQUS. version 6.10. Simulia, Dassault Systèmes, France, 2010.

874 [39] Arrayago I., Picci F., Mirambell E. and Real E. Interaction of bending and axial load for ferritic stainless steel RHS columns. Thin-Walled Structures 91, 96-107, 2015.

[40] Huang Y. and Young B. Design of cold-formed lean duplex stainless steel members in combined compression and bending. Journal of Structural Engineering (ASCE) 141(5): 04014138, 2015.

878 [41] Jandera M., Gardner L. and Machacek J. Residual stresses in cold-rolled stainless steel hollow sections. Journal of Constructional Steel Research 64 (11), 1255-1263, 2008.

880 [42] Rasmussen K.J.R. and Hancock G.J. Design of cold-formed stainless steel tubular members. I: Columns. Journal of Structural Engineering (ASCE) 119(8), 2349-2367, 1993. imperfection characteristics of structural stainless steels and members. Journal of Constructional Steel Research 175, 106378, 2020.

885 [44] Holický M., Retief J.V. and Sýkora M. Assessment of model uncertainties for structural resistance. 
[45] European Committee for Standardization (CEN). EN 1990:2005. Eurocode: Basis of Structural

888 Design. Brussels, Belgium, 2005.

889 [46] Gulvanessian H. and Holicky M. Eurocodes: using reliability analysis to combine action effects.

890 Proceedings of the Institution of Civil Engineers, Structures \& Buildings 158(SB4), 243-252, 2005.

891 [47] Joint Committee on Structural Safety (JCSS). Probabilistic Model Code, Zurich, Switzerland, 2001.

892 [48] European Committee for Standardization (CEN). EN 1991-1-1. Eurocode 1: Actions on structures

893 - Part 1-1: General actions. Densities, self-weight, imposed loads for buildings. Brussels, Belgium, 8942002.

895 [49] American Society of Civil Engineers (ASCE). ASCE 7. Minimum design loads and associated 896 criteria for buildings and other structures. Virginia, USA, 2016.

897 [50] AS/NZS 1170.1. Structural design actions, Part 1: Permanent, imposed and other actions. 898 Standards Australia, Sydney, Australia, 2016.

899 [51] Ellingwood B.R., MacGregor J.G., Galambos T.V. and Cornell C.A. Probability based load 900 criteria: Load factors and load combinations. Journal of Structural Division 108(5), 978-997, 1982.

901 [52] Honfi D., A. Mårtensson A. and Thelandersson S. Reliability of beams according to Eurocodes in 902 serviceability limit state. Engineering Structures 35, 48-54, 2012.

903 [53] Holický M. Implementation of Eurocodes. Handbook 3: Action effects for buildings. Chapter I - Self904 weight and imposed loads on buildings. Leonardo da Vinci Pilot Project CZ/02/B/F/PP-134007, 2005.

905 [54] AS/NZS 1170.0 Structural design actions, Part 0: General principles. Standards Australia, Sydney, 906 Australia, 2002.

907 [55] Melchers R.E. Structural reliability analysis and prediction. John Wiley \& Sons, 1999.

908 [56] Ziemian R.D., McGuire W. and Deierlein G.G. Inelastic limit states design. Part I: planar frame 909 studies. Journal of Structural Engineering (ASCE) 118(9), 2532-2549, 1992.

910 [57] MATLAB version 9.8.0 (R2020a). The MathWorks Inc., Natick, Massachusetts, 2020.

911 [58] Lefebvre M. Applied Probability and Statistics. Springer Science+Business Media LLC, 2006.

912 [59] McAllister T.P., Wang N. and Ellingwood B.R. Risk-informed mean recurrence intervals for 913 updated wind maps in ASCE 7-16. Journal of Structural Engineering (ASCE) 144(5):06018001, 2018. 
914 [60] Ellingwood B.R. Acceptable risk bases for design of structures. Progress in Structural Engineering 915 and Materials 3(2), 170-179, 2001.

916 [61] Ellingwood B.R. LRFD: implementing structural reliability in professional practice. Engineering

917 Structures 22, 106-15, 2000.

918 [62] Ad Hoc Group for Eurocode 0 CEN/TC 250/SC10. Reliability Technical Report for the reliability 919 background of Eurocodes. Draft document, August 2020.

920 [63] Vrouwenvelder A.C.W.M. and Siemes A.J.M. Probabilistic calibration procedure for the derivation 921 of partial safety factors for the Netherlands building codes. HERON 32 (4), 9-31, 1987.

922 [64] Galambos T.V., Ellingwood B.R., MacGregor J.G. and Cornell C.A. Probability Based Load 923 Criteria: Assessment of Current Design Practice. Journal of the Structural Division (ASCE) 108(5), 924 959-977, 1982.

925 [65] Ellingwood B.R. and Tekie P.B. Wind load statistics for probability-based structural design. 926 Journal of Structural Engineering 125(4), 453-463, 1999. 


\section{FIGURES}
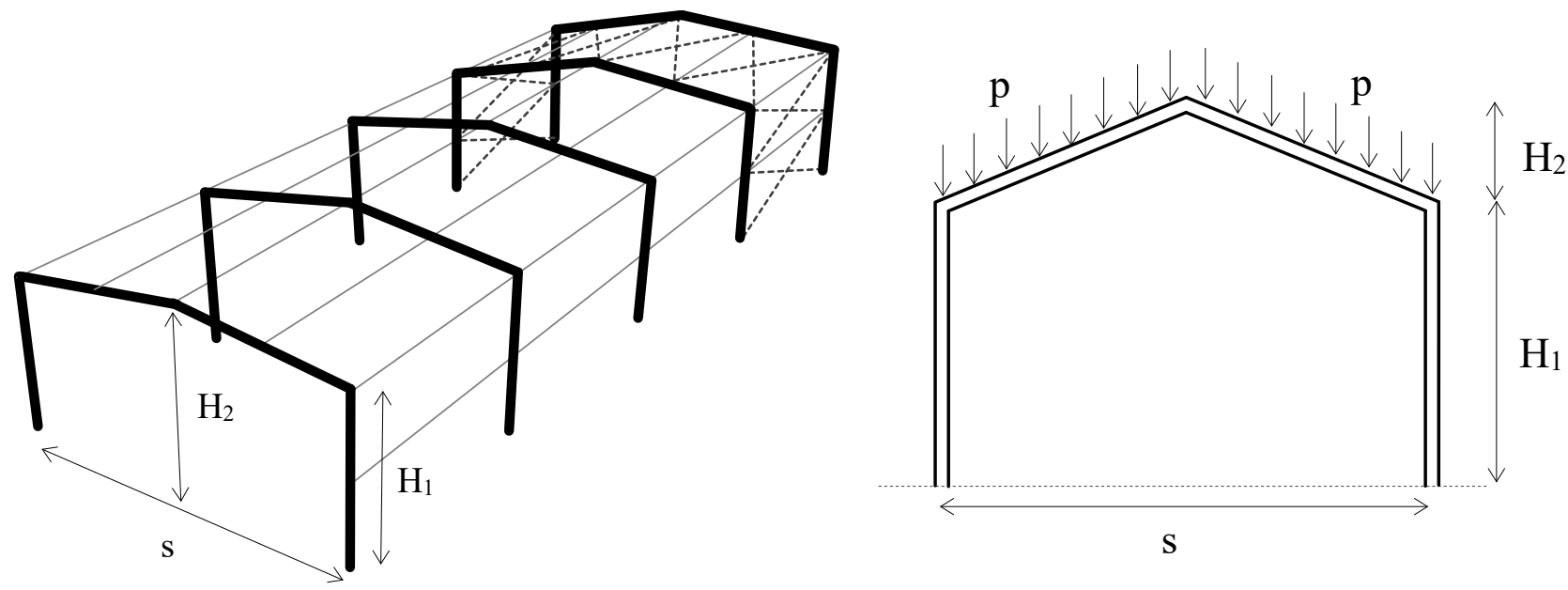

Figure 1. General layout of investigated frames.

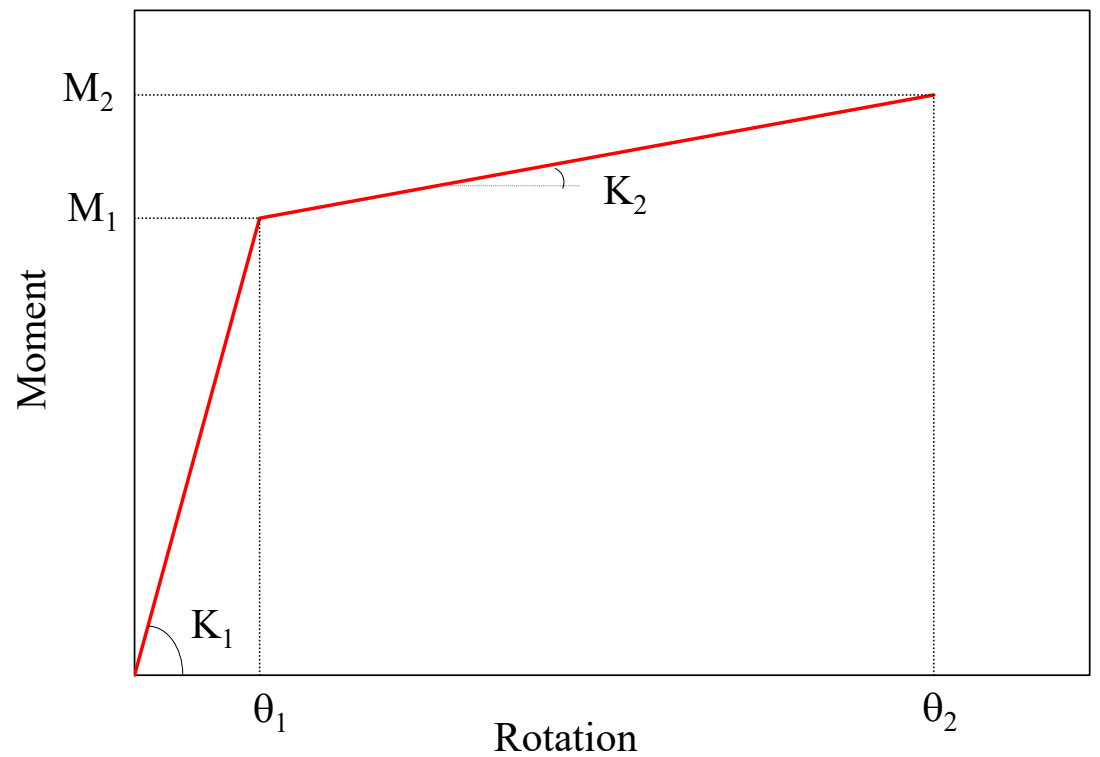

Figure 2. Constitutive moment-rotation model adopted for connection behaviour. 


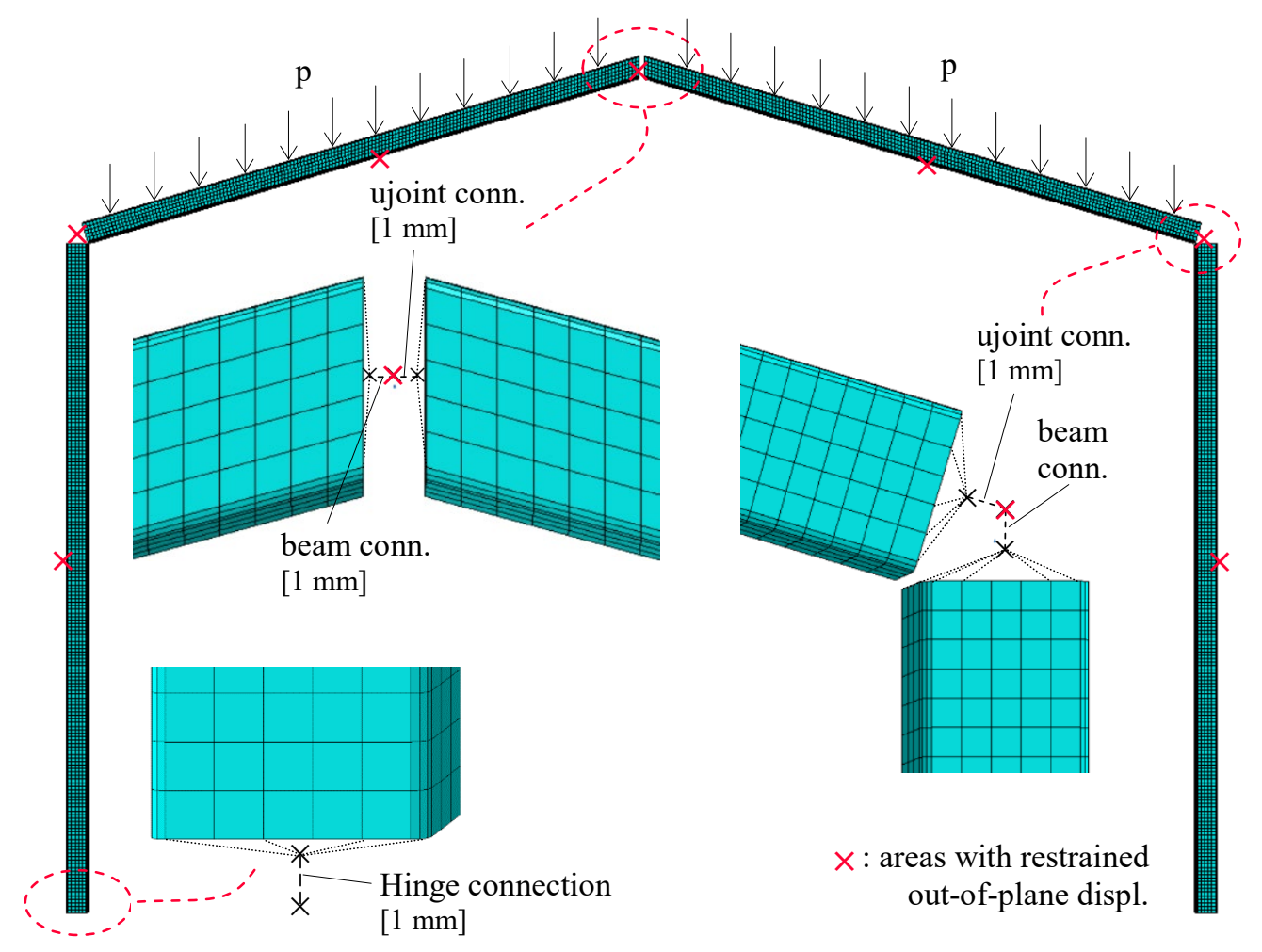

Figure 3. Overall view of developed FE model and definition of vertical loading and joints.
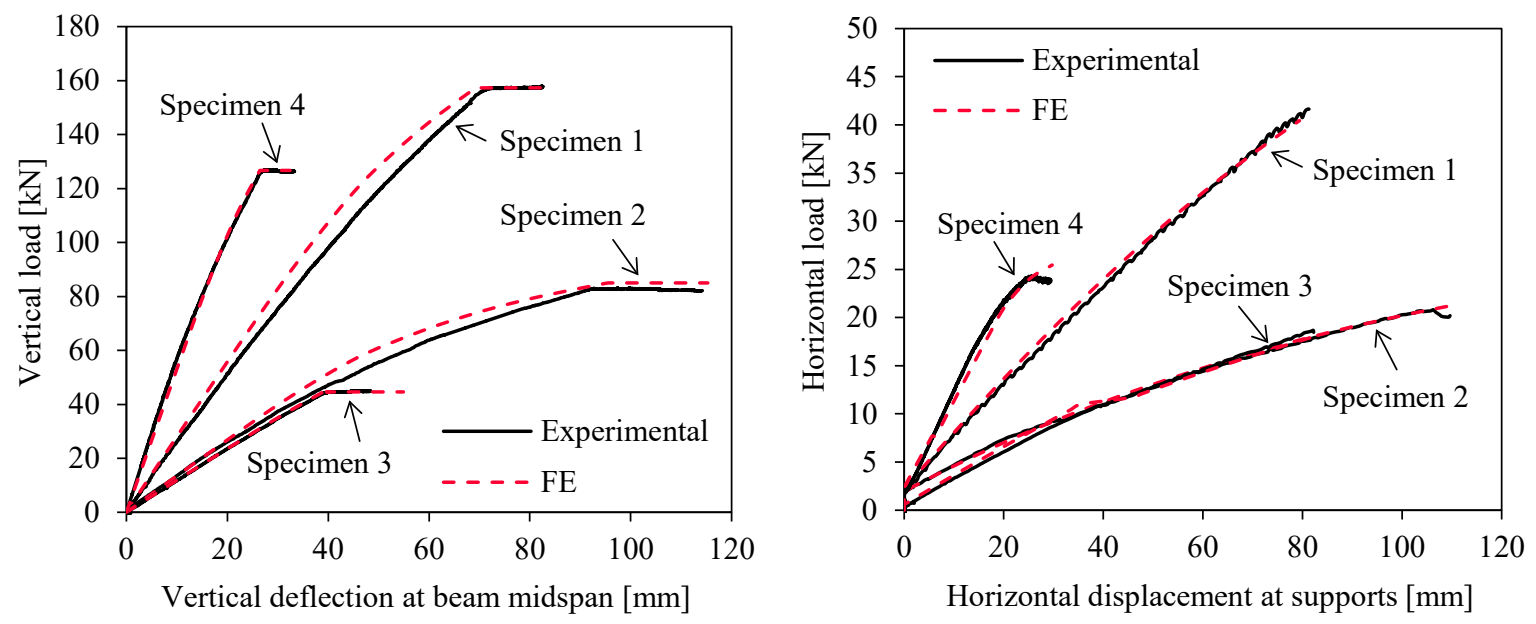

Figure 4. Comparison of FE and experimental load-deflection and load-displacement curves. 

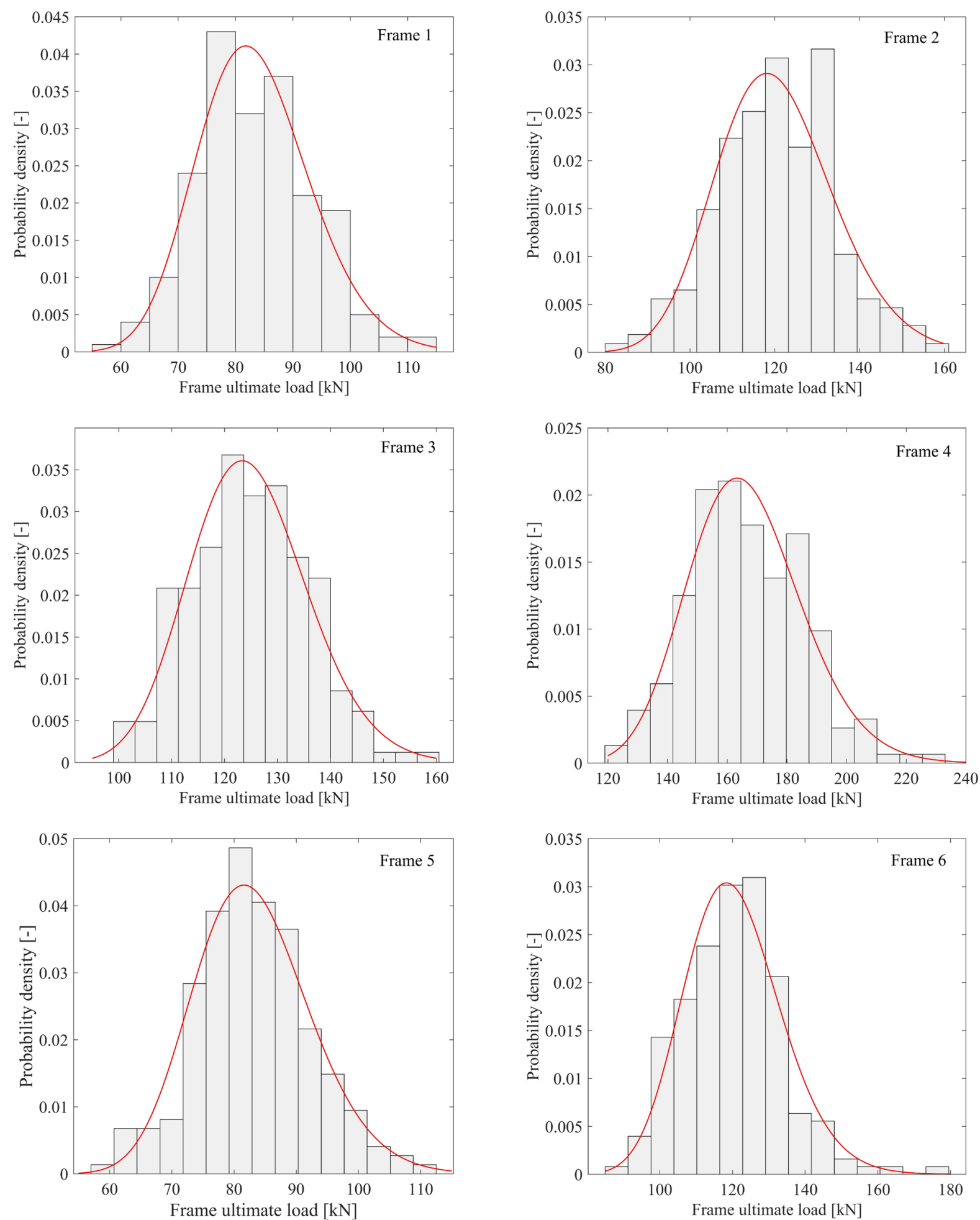

Figure 5. Histograms for system strength of stainless steel frames under gravity loads. 
(a) Frame 1

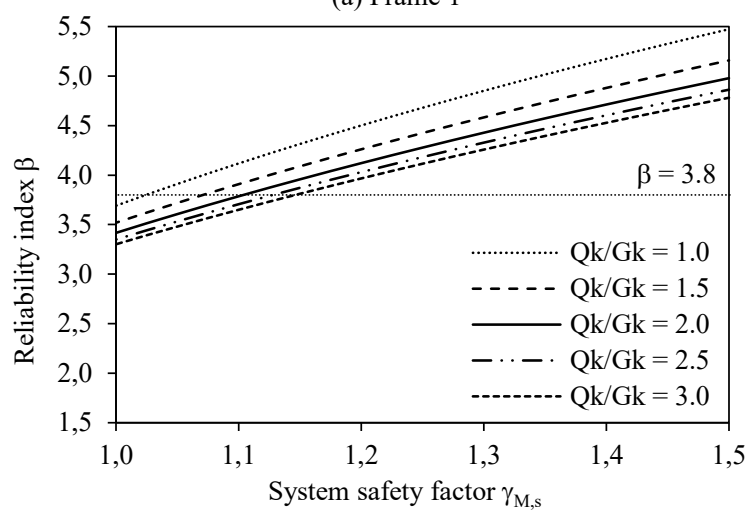

(c) Frame 3

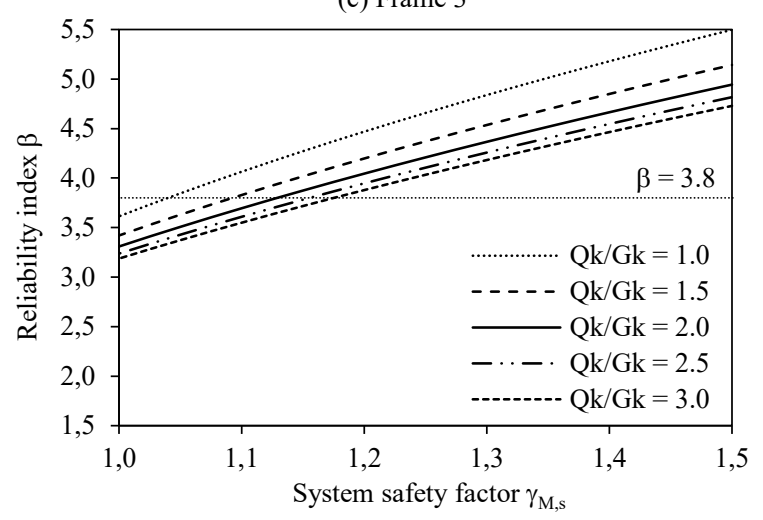

(e) Frame 5

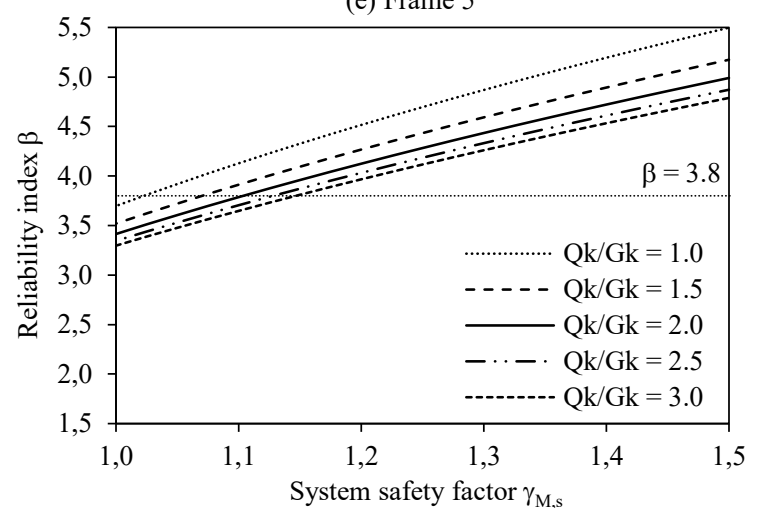

(b) Frame 2

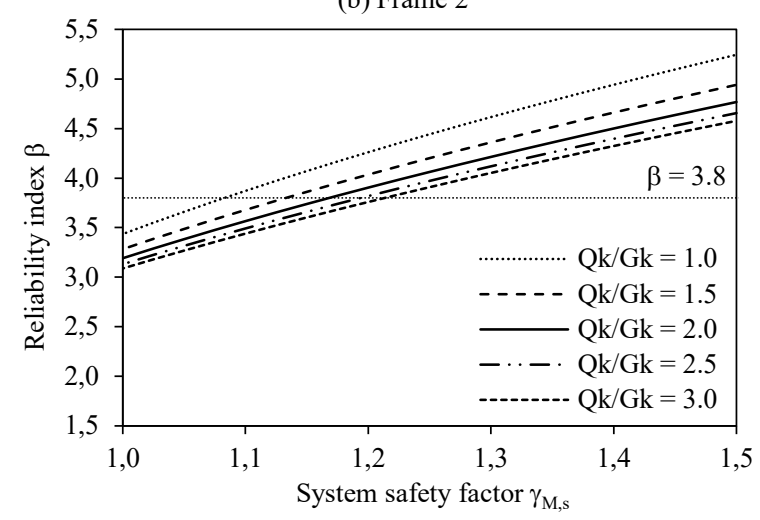

(d) Frame 4

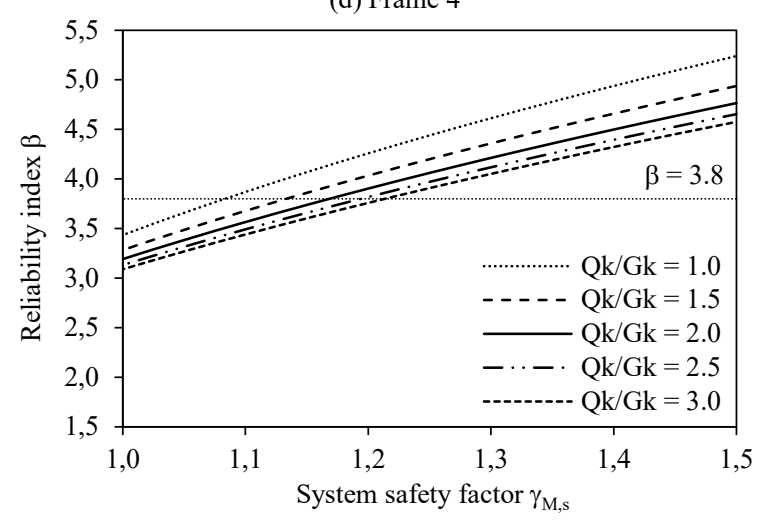

(f) Frame 6

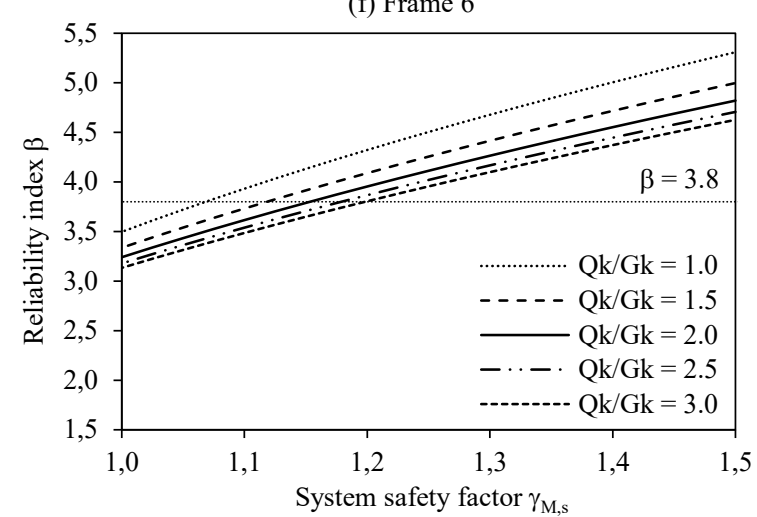

Figure 6. $\beta-\gamma_{\mathrm{M}, \mathrm{S}}$ curves for stainless steel frames under gravity loads in the Eurocode framework for different $Q_{k} / G_{k}$ ratios. 
(a) Frame 1

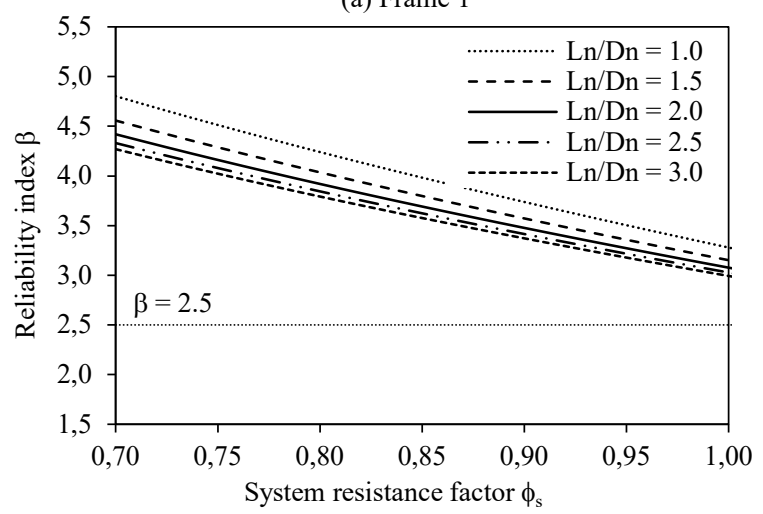

(c) Frame 3

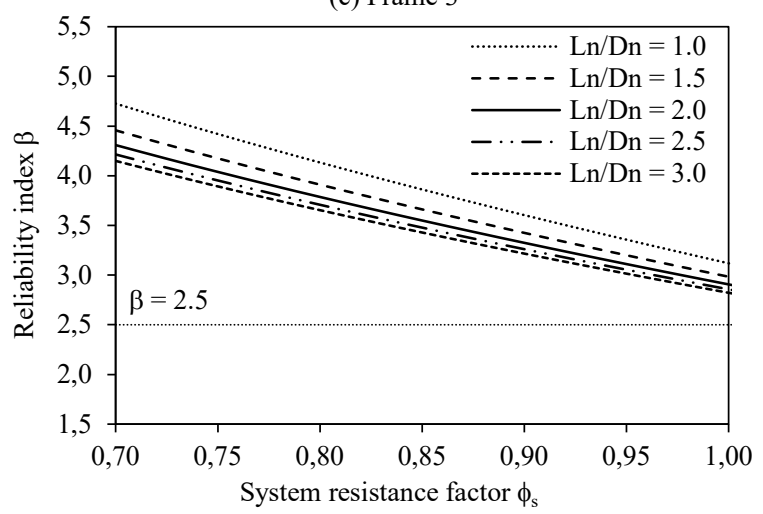

(e) Frame 5

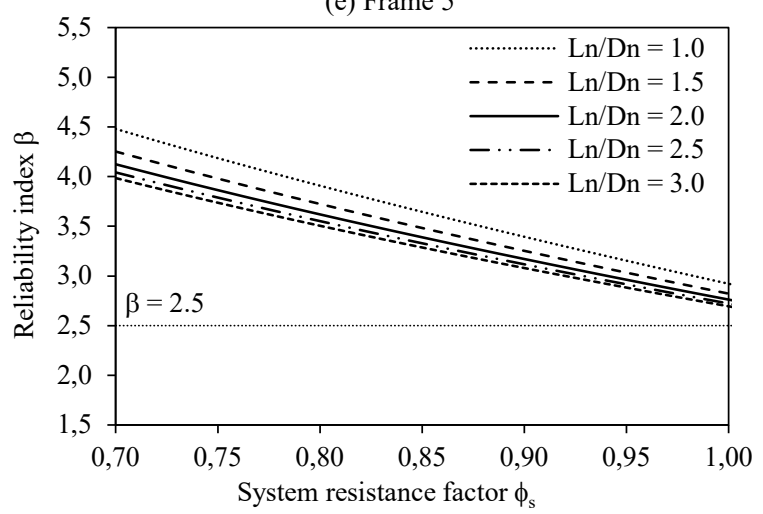

(b) Frame 2

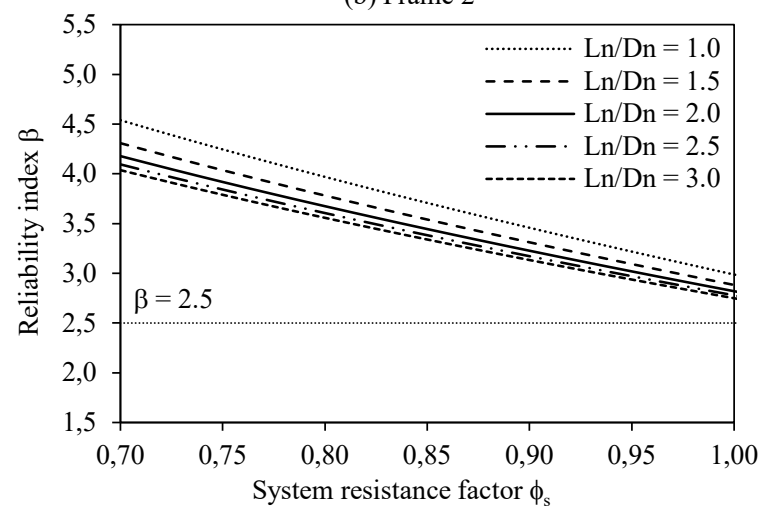

(d) Frame 4

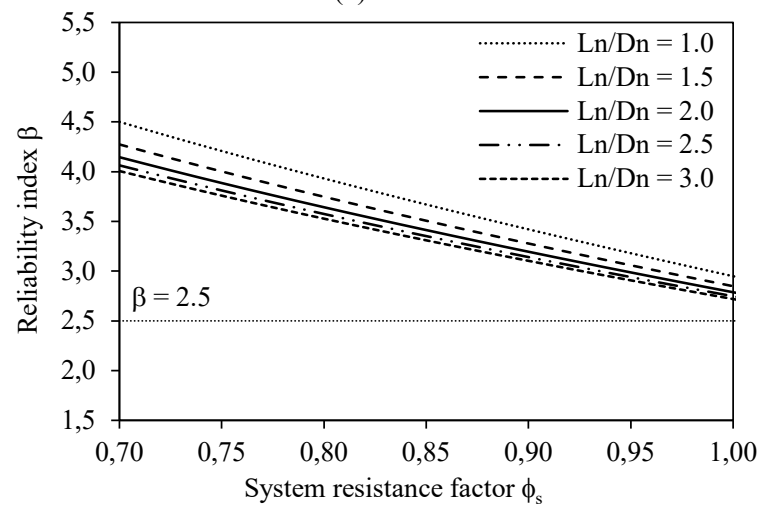

(f) Frame 6

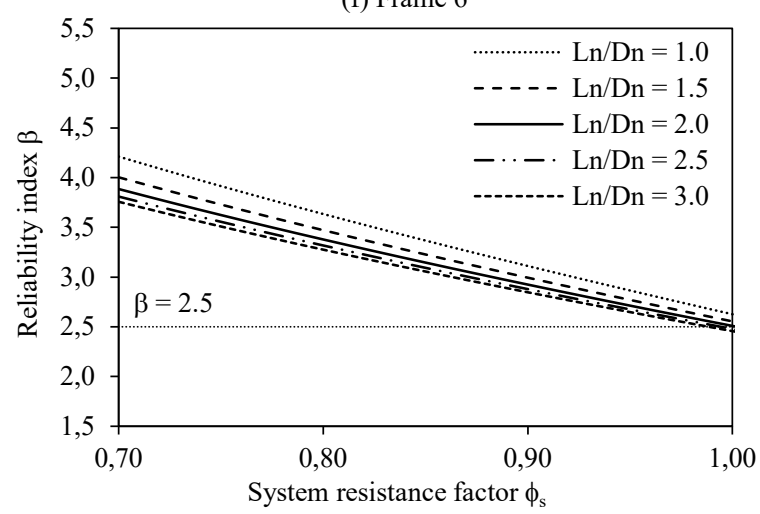

Figure 7. $\beta-\phi_{\mathrm{S}}$ curves for stainless steel frames under gravity loads in the US framework for different $L_{n} / D_{n}$ ratios. 
(a) Frame 1

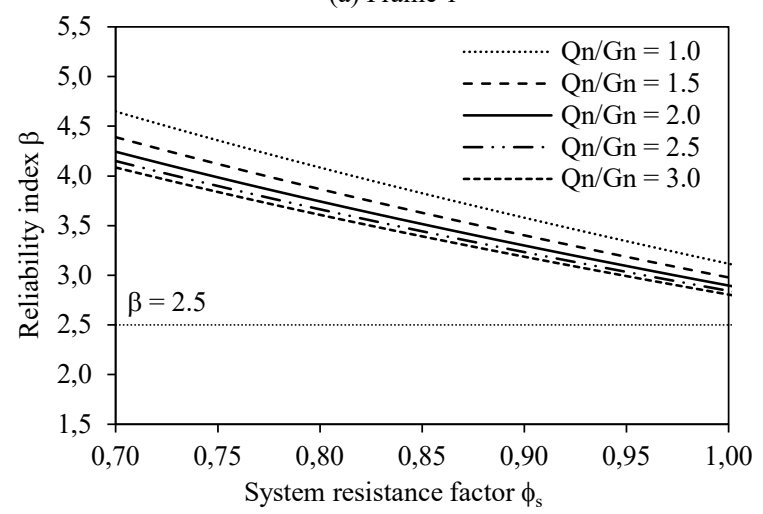

(c) Frame 3

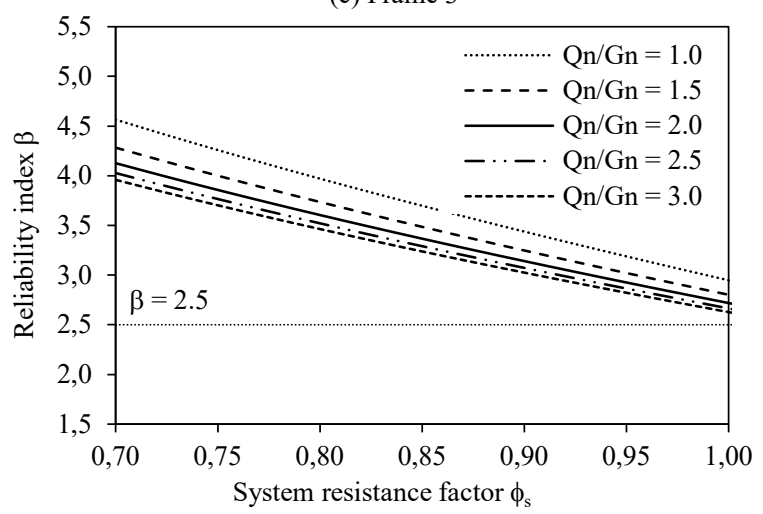

(e) Frame 5

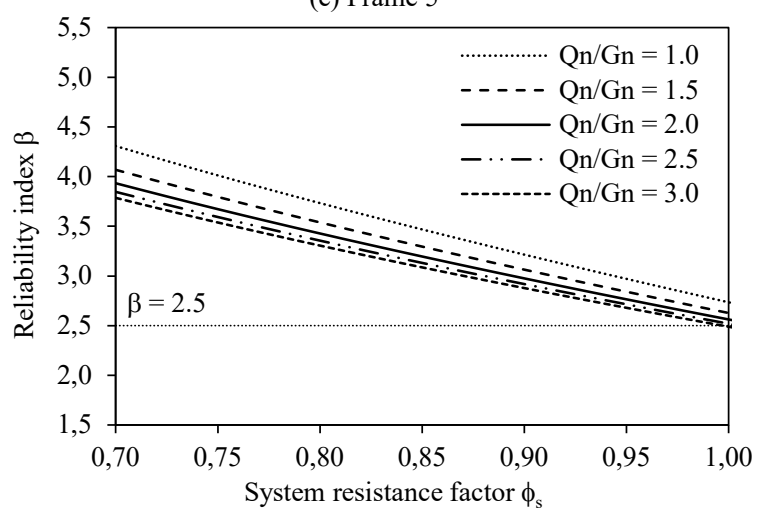

(b) Frame 2

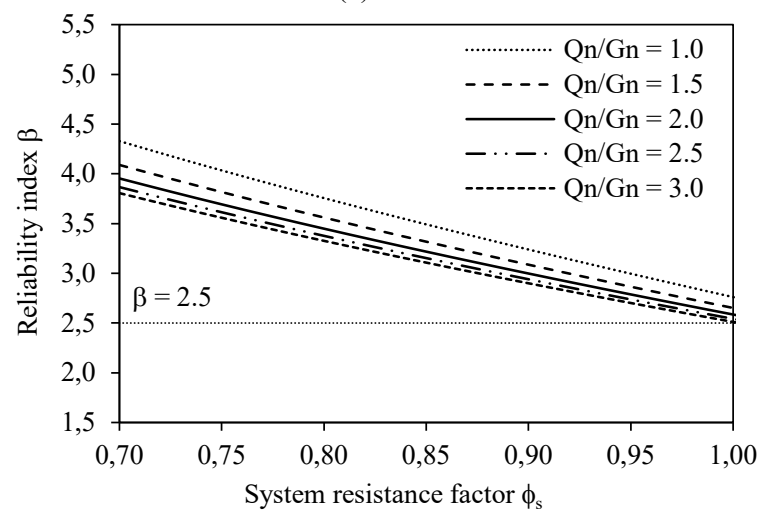

(d) Frame 4

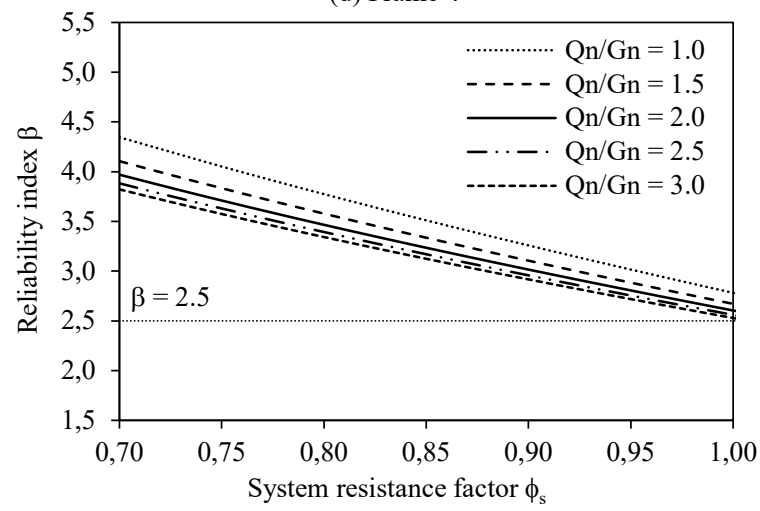

(f) Frame 6

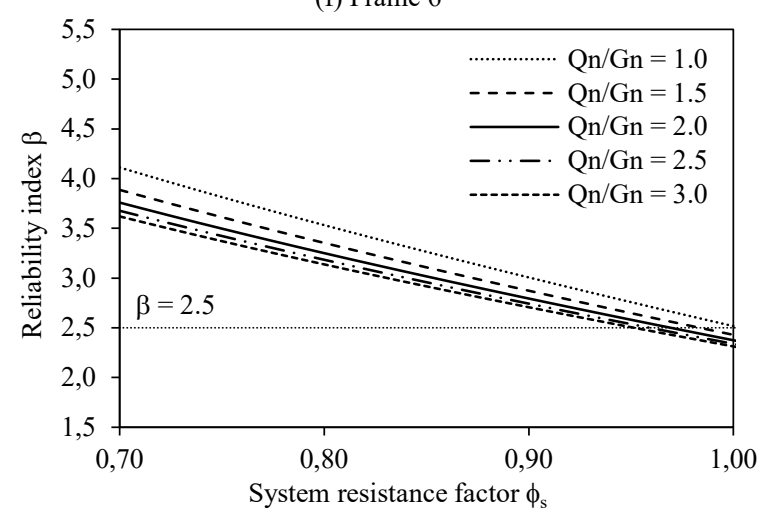

Figure 8. $\beta-\phi_{\mathrm{s}}$ curves for stainless steel frames under gravity loads in the Australian framework for different $Q_{n} / G_{n}$ ratios. 


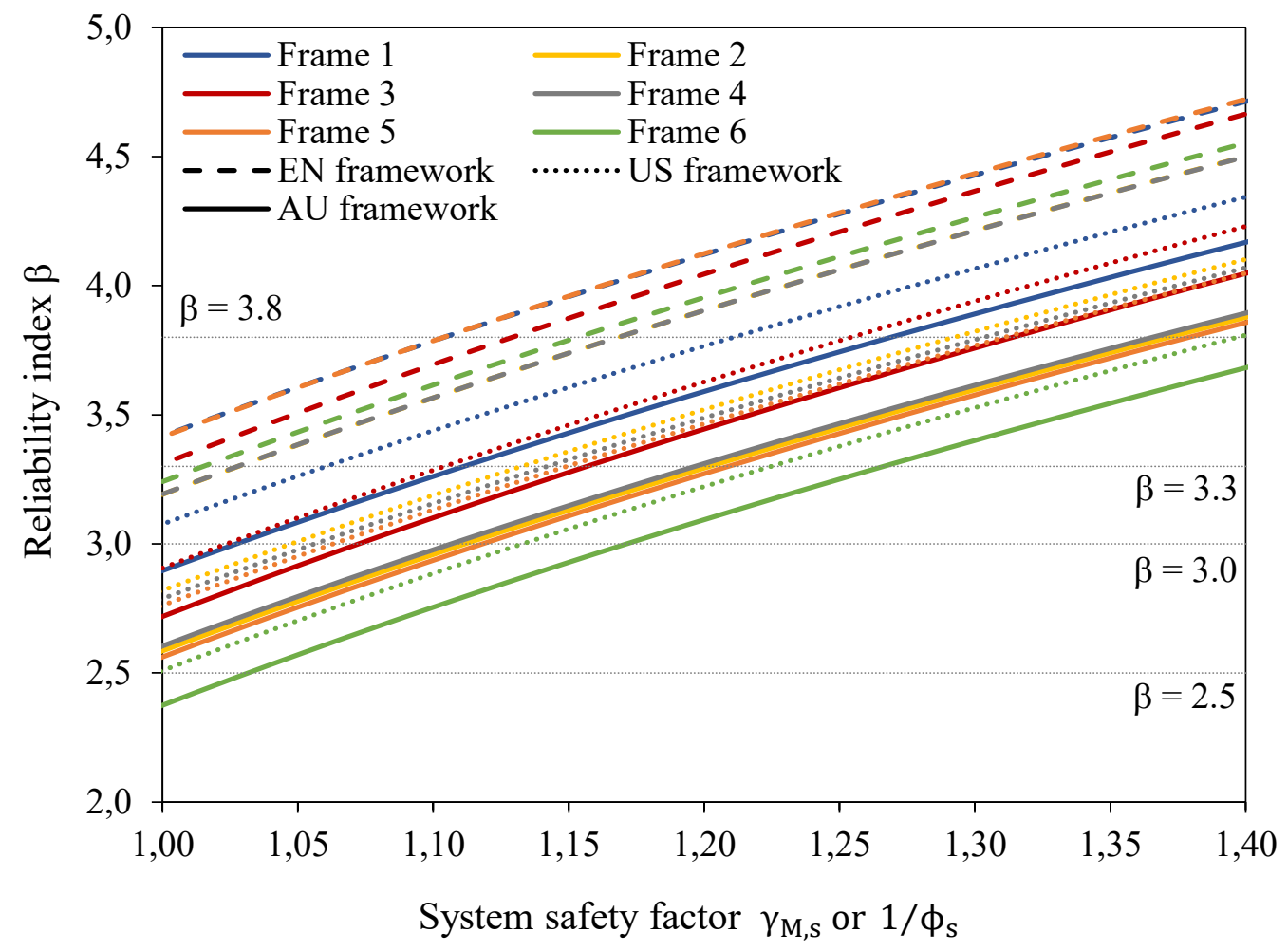

Figure 9. Comparison of $\beta-\gamma_{\mathrm{M}, \mathrm{s}}$ and $\beta-1 / \phi_{\mathrm{s}}$ curves for stainless steel frames under gravity loads for $Q_{k} / G_{k}=2, L_{n} / D_{n}=2$ or $Q_{n} / G_{n}=2$. 


\section{TABLES}

Table 1. Key parameters for nominal stainless steel frames.

Austenitic Duplex Ferritic

stainless steel stainless steel

stainless steel

\begin{tabular}{|c|c|c|c|c|c|c|c|}
\hline Variable group & Variable & Frame 1 & Frame 2 & Frame 3 & Frame 4 & Frame 5 & Frame 6 \\
\hline \multirow{3}{*}{$\begin{array}{l}\text { Overall frame } \\
\text { geometry }\end{array}$} & $\mathrm{s}[\mathrm{m}]$ & 8.0 & 10.0 & 8.0 & 12.0 & 8.0 & 11.0 \\
\hline & $\mathrm{H}_{1}[\mathrm{~m}]$ & 4.8 & 6.4 & 4.8 & 6.6 & 4.8 & 6.5 \\
\hline & $\mathrm{H}_{2}[\mathrm{~m}]$ & 6.0 & 7.0 & 6.0 & 7.4 & 6.0 & 7.2 \\
\hline \multirow{3}{*}{$\begin{array}{l}\text { Cross-section } \\
\text { definition }\end{array}$} & $\mathrm{H}[\mathrm{mm}]$ & 150 & 250 & 150 & 250 & 150 & 250 \\
\hline & $\mathrm{B}[\mathrm{mm}]$ & 100 & 150 & 100 & 150 & 100 & 150 \\
\hline & $\mathrm{t}[\mathrm{mm}]$ & 4 & 4 & 4 & 4 & 4 & 4 \\
\hline \multirow{3}{*}{$\begin{array}{c}\text { Initial } \\
\text { geometric } \\
\text { imperfections }\end{array}$} & Frame imp. $\phi[-]$ & $\begin{array}{l}1 / 200^{+} \\
1 / 500^{*}\end{array}$ & $\begin{array}{l}1 / 200^{+} \\
1 / 500^{*}\end{array}$ & $\begin{array}{l}1 / 200^{+} \\
1 / 500^{*}\end{array}$ & $\begin{array}{l}1 / 200^{+} \\
1 / 500^{*}\end{array}$ & $\begin{array}{l}1 / 200^{+} \\
1 / 500^{*}\end{array}$ & $\begin{array}{l}1 / 200^{+} \\
1 / 500^{*}\end{array}$ \\
\hline & Member imp. $\mathrm{e}_{0}[\mathrm{~mm}]$ & $\mathrm{L} / 1000$ & $\mathrm{~L} / 1000$ & $\mathrm{~L} / 1000$ & $\mathrm{~L} / 1000$ & $\mathrm{~L} / 1000$ & $\mathrm{~L} / 1000$ \\
\hline & Local imp. $\mathrm{w}_{0}[\mathrm{~mm}]$ & 0.017 & 0.040 & 0.030 & 0.072 & 0.017 & 0.043 \\
\hline \multirow{4}{*}{$\begin{array}{c}\text { Joint behaviour } \\
\text { at bases }\end{array}$} & $\mathrm{K}_{1, \text { base }}[\mathrm{kNm} / \mathrm{rad}]$ & 4000 & Pinned & 4000 & Pinned & 4000 & Pinned \\
\hline & $\mathrm{K}_{2, \text { base }}[\mathrm{kNm} / \mathrm{rad}]$ & 400 & - & 400 & - & 400 & - \\
\hline & $\mathrm{M}_{1, \text { base }}[\mathrm{kNm}]$ & 26.3 & - & 41.4 & - & 27.0 & - \\
\hline & $\mathrm{M}_{2, \text { base }}[\mathrm{kNm}]$ & 40.4 & - & 63.4 & - & 41.4 & - \\
\hline \multirow{4}{*}{$\begin{array}{l}\text { Joint behaviour } \\
\text { at eaves }\end{array}$} & $\mathrm{K}_{1, \text { eave }}[\mathrm{kNm} / \mathrm{rad}]$ & 6400 & 7000 & 6400 & 9000 & 6400 & 8000 \\
\hline & $\mathrm{K}_{2, \text { eave }}[\mathrm{kNm} / \mathrm{rad}]$ & 640 & 700 & 640 & 900 & 640 & 800 \\
\hline & $\mathrm{M}_{1, \text { eave }}[\mathrm{kNm}]$ & 23.9 & 50.0 & 37.6 & 86.4 & 24.6 & 51.5 \\
\hline & $\mathrm{M}_{2, \text { eave }}[\mathrm{kNm}]$ & 37.4 & 78.2 & 58.7 & 105.4 & 38.4 & 80.5 \\
\hline \multirow{4}{*}{$\begin{array}{c}\text { Joint behaviour } \\
\text { at apex }\end{array}$} & $\mathrm{K}_{1, \text { apex }}[\mathrm{kNm} / \mathrm{rad}]$ & 6600 & 7500 & 6600 & 9500 & 6600 & 8500 \\
\hline & $\mathrm{K}_{2, \text { apex }}[\mathrm{kNm} / \mathrm{rad}]$ & 660 & 750 & 660 & 950 & 660 & 850 \\
\hline & $\mathrm{M}_{1, \text { apex }}[\mathrm{kNm}]$ & 25.4 & 53.1 & 39.9 & 91.8 & 26.1 & 54.8 \\
\hline & $\mathrm{M}_{2, \text { apex }}[\mathrm{kNm}]$ & 37.4 & 78.2 & 58.7 & 105.4 & 38.4 & 80.5 \\
\hline
\end{tabular}

${ }^{+}:$Frame imperfection corresponding to prEN 1993-1-1 [1] and prEN 1993-1-14 [11].

*: Frame imperfection corresponding to AS/NZS 4100 [3], AISC 360 [4] or AISC 370 [10].

Table 2. Nominal material parameters for frames in the Eurocode framework $[2,35]$.
Austenitic
Duplex
Ferritic
EN 1.4301
EN 1.4462
EN 1.4003

\begin{tabular}{ccccccc}
\hline Variable & Frame 1 & Frame 2 & Frame 3 & Frame 4 & Frame 5 & Frame 6 \\
\hline $\mathrm{E}[\mathrm{MPa}]$ & 200000 & 200000 & 200000 & 200000 & 200000 & 200000 \\
$\mathrm{f}_{\mathrm{y}}[\mathrm{MPa}]$ & 230 & 230 & 500 & 500 & 280 & 280 \\
$\mathrm{f}_{\mathrm{y}, \mathrm{enh}}[\mathrm{MPa}]$ & 297 & 279 & 507 & 503 & 299 & 300 \\
$\mathrm{n}[-]$ & 7 & 7 & 8 & 8 & 14 & 14 \\
$\mathrm{f}_{\mathrm{u}}[\mathrm{MPa}]$ & 550 & 550 & 700 & 700 & 450 & 450 \\
$\varepsilon_{\mathrm{u}}[\mathrm{mm} / \mathrm{mm}]$ & 0.46 & 0.49 & 0.28 & 0.28 & 0.20 & 0.20 \\
$\mathrm{~m}[-]$ & 2.5 & 2.4 & 3.0 & 3.0 & 2.9 & 2.9 \\
\hline
\end{tabular}


Table 3. Nominal material parameters for frames in the US framework [20].

\begin{tabular}{ccccccc} 
& \multicolumn{2}{c}{ Austenitic } & \multicolumn{2}{c}{ Duplex } & \multicolumn{2}{c}{ Ferritic } \\
& \multicolumn{2}{c}{ ASTM 304 } & \multicolumn{2}{c}{ ASTM 2205 } & ASTM UNS S40977 \\
\hline Variable & Frame 1 & Frame 2 & Frame 3 & Frame 4 & Frame 5 & Frame 6 \\
\hline $\mathrm{E}[\mathrm{MPa}]$ & 193000 & 193000 & 200000 & 200000 & 200000 & 200000 \\
$\mathrm{f}_{\mathrm{y}}[\mathrm{MPa}]$ & 205 & 205 & 450 & 450 & $280^{*}$ & $280^{*}$ \\
$\mathrm{f}_{\mathrm{y}, \mathrm{enh}}[\mathrm{MPa}]$ & 271 & 254 & 465 & 454 & 299 & 296 \\
$\mathrm{n}[-]$ & 7 & 7 & 8 & 8 & 14 & 14 \\
$\mathrm{f}_{\mathrm{u}}[\mathrm{MPa}]$ & 515 & 515 & 655 & 655 & $435^{*}$ & $435^{*}$ \\
$\varepsilon_{\mathrm{u}}[\mathrm{mm} / \mathrm{mm}]$ & 0.47 & 0.51 & 0.29 & 0.31 & 0.19 & 0.19 \\
$\mathrm{~m}[-]$ & 2.5 & 2.4 & 3.0 & 2.9 & 2.9 & 2.9 \\
\hline
\end{tabular}

*: Nominal material parameters correspond to the AS/NZS 4673 [22] Specification.

Table 4. Nominal material parameters for frames in the Australian framework [22].

$\begin{array}{ccc}\text { Austenitic } & \text { Duplex } & \text { Ferritic } \\ \text { ASTM 304 } & \text { ASTM 2205 } & \text { ASTM UNS S40977 }\end{array}$

\begin{tabular}{ccccccc}
\hline Variable & Frame 1 & Frame 2 & Frame 3 & Frame 4 & Frame 5 & Frame 6 \\
\hline $\mathrm{E}[\mathrm{MPa}]$ & 195000 & 195000 & $200000^{*}$ & $200000^{*}$ & 195000 & 195000 \\
$\mathrm{f}_{\mathrm{y}}[\mathrm{MPa}]$ & 205 & 205 & $450^{*}$ & $450^{*}$ & 280 & 280 \\
$\mathrm{f}_{\mathrm{y}, \mathrm{enh}}[\mathrm{MPa}]$ & 273 & 255 & 465 & 454 & 299 & 296 \\
$\mathrm{n}[-]$ & 7.5 & 7.5 & $8^{*}$ & $8^{*}$ & 9 & 9 \\
$\mathrm{f}_{\mathrm{u}}[\mathrm{MPa}]$ & 520 & 520 & $655^{*}$ & $655^{*}$ & 435 & 435 \\
$\varepsilon_{\mathrm{u}}[\mathrm{mm} / \mathrm{mm}]$ & 0.48 & 0.51 & 0.29 & 0.31 & 0.19 & 0.19 \\
$\mathrm{~m}[-]$ & 2.5 & 2.4 & 3.0 & 2.9 & 2.9 & 2.9 \\
\hline
\end{tabular}

*: Nominal material parameters correspond to the ASCE 8 [20] Specification.

Table 5. Comparison of FE and experimental results.

\begin{tabular}{ccccc}
\hline Specimen & $\mathrm{F}_{\mathrm{v}, \mathrm{FE}} / \mathrm{F}_{\mathrm{v}, \exp }$ & $\mathrm{d}_{\mathrm{v}, \mathrm{FE}} / \mathrm{d}_{\mathrm{v}, \exp }$ & $\mathrm{F}_{\mathrm{h}, \mathrm{FE}} / \mathrm{F}_{\mathrm{h}, \exp }$ & $\mathrm{d}_{\mathrm{h}, \mathrm{FE}} / \mathrm{d}_{\mathrm{h}, \exp }$ \\
\hline Specimen 1 & 1.00 & 1.01 & 1.00 & 1.02 \\
Specimen 2 & 1.00 & 1.02 & 1.00 & 0.99 \\
Specimen 3 & 1.00 & 0.99 & 1.00 & 1.05 \\
Specimen 4 & 1.00 & 1.03 & 1.00 & 1.01 \\
\hline Mean & 1.00 & 1.01 & 1.00 & 1.02 \\
COV & 0.000 & 0.017 & 0.000 & 0.024 \\
\hline
\end{tabular}


Table 6. Statistics of random variables defining frame strength.

\begin{tabular}{|c|c|c|c|c|c|c|}
\hline $\begin{array}{c}\text { Random } \\
\text { variable type }\end{array}$ & $\begin{array}{l}\text { Random } \\
\text { variable }\end{array}$ & Mean & St. Deviation & $\mathrm{COV}$ & $\begin{array}{c}\text { Statistical } \\
\text { distribution }\end{array}$ & Reference \\
\hline \multirow{3}{*}{$\begin{array}{l}\text { Cross-section } \\
\text { definition }\end{array}$} & $\mathrm{H}[\mathrm{mm}]$ & $1.002 \cdot \mathrm{H}_{\mathrm{n}}$ & $0.012 \cdot \mathrm{H}_{\mathrm{n}}$ & 0.012 & Normal & \multirow{3}{*}{ [43] } \\
\hline & $\mathrm{B}[\mathrm{mm}]$ & $1.002 \cdot \mathrm{B}_{\mathrm{n}}$ & $0.010 \cdot \mathrm{B}_{\mathrm{n}}$ & 0.010 & Normal & \\
\hline & $\mathrm{t}[\mathrm{mm}]$ & $0.974 \cdot \mathrm{t}_{\mathrm{n}}$ & $0.028 \cdot t_{n}$ & 0.029 & Normal & \\
\hline \multirow{3}{*}{$\begin{array}{c}\text { Initial } \\
\text { geometric } \\
\text { imperfections }\end{array}$} & $\begin{array}{c}\text { Frame imp. } \\
\quad \phi[-]\end{array}$ & 0.0 & $1 / 610$ & - & Normal & [9] \\
\hline & $\begin{array}{l}\text { Member imp. } \\
\mathrm{e}_{0}[\mathrm{~mm}]\end{array}$ & $\mathrm{L} / 3232$ & $\mathrm{~L} / 5369$ & 0.602 & Log-normal & [43] \\
\hline & $\begin{array}{c}\text { Local imp. } \\
\gamma_{2}[-]\end{array}$ & 0.041 & 0.026 & 0.636 & Log-normal & {$[43]$} \\
\hline $\begin{array}{c}\text { Residual } \\
\text { stresses }\end{array}$ & Scale Factor Y & 0.875 & 0.161 & 0.184 & Normal & {$[43]$} \\
\hline \multirow{4}{*}{$\begin{array}{c}\text { Joint } \\
\text { behaviour }\end{array}$} & $\mathrm{K}_{1}[\mathrm{kNm} / \mathrm{rad}]$ & $1.0 \cdot \mathrm{K}_{1, \mathrm{n}}$ & $0.30 \cdot \mathrm{K}_{1, \mathrm{n}}$ & 0.300 & Log-normal & \multirow{4}{*}{ [9] } \\
\hline & $\mathrm{K}_{2}[\mathrm{kNm} / \mathrm{rad}]$ & $1.0 \cdot \mathrm{K}_{2, \mathrm{n}}$ & $0.15 \cdot \mathrm{K}_{2, \mathrm{n}}$ & 0.150 & Log-normal & \\
\hline & $\mathrm{M}_{1}[\mathrm{kNm}]$ & $1.0 \cdot \mathrm{M}_{1, \mathrm{n}}$ & $0.10 \cdot \mathrm{M}_{1, \mathrm{n}}$ & 0.100 & Log-normal & \\
\hline & $\mathrm{M}_{2}[\mathrm{kNm}]$ & $1.0 \cdot \mathrm{M}_{2, \mathrm{n}}$ & $0.15 \cdot \mathrm{M}_{2, \mathrm{n}}$ & 0.150 & Log-normal & \\
\hline $\begin{array}{c}\text { Model } \\
\text { uncertainty }\end{array}$ & $\theta$ or $\gamma_{\mathrm{FE}}$ & 1.0 & 0.05 & 0.05 & Log-normal & {$[46,47]$} \\
\hline
\end{tabular}

Note: the subscript $n$ represents the nominal value and $\mathrm{L}$ is the length of the member.

Table 7. Statistics of material random variables for cold-formed stainless steel alloys [43].

\begin{tabular}{cccccc}
\hline Alloy family & Random variable & Mean & St. Deviation & COV & $\begin{array}{c}\text { Statistical } \\
\text { distribution }\end{array}$ \\
\hline & $\mathrm{E}[\mathrm{MPa}]$ & 193084 & 11039 & 0.057 & Normal \\
Austenitic & $\mathrm{f}_{\mathrm{y}}$ & $1.30 \cdot \mathrm{f}_{\mathrm{y}, \mathrm{enh}, \mathrm{n}}$ & $0.195 \cdot \mathrm{f}_{\mathrm{y}, \mathrm{enh}, \mathrm{n}}$ & 0.150 & Log-normal \\
cold-formed & $\mathrm{n}[-]$ & 6.0 & 2.1 & 0.342 & Log-normal \\
& $\mathrm{f}_{\mathrm{u}}$ & $1.10 \cdot \mathrm{f}_{\mathrm{u}, \mathrm{n}}$ & $0.11 \cdot \mathrm{f}_{\mathrm{u}, \mathrm{n}}$ & 0.100 & Log-normal \\
& $\varepsilon_{\mathrm{u}}[\mathrm{mm} / \mathrm{mm}]$ & 0.39 & 0.15 & 0.373 & Normal \\
& $\mathrm{m}[-]$ & 3.1 & 1.3 & 0.426 & Log-normal \\
\hline Duplex & $\mathrm{E}[\mathrm{MPa}]$ & 205025 & 8700 & 0.042 & Normal \\
cold-formed & $\mathrm{f}_{\mathrm{y}}$ & $1.15 \cdot \mathrm{f}_{\mathrm{y}, \mathrm{enh}, \mathrm{n}}$ & $0.173 \cdot \mathrm{f}_{\mathrm{y}, \mathrm{enh}, \mathrm{n}}$ & 0.150 & Log-normal \\
& $\mathrm{n}[-]$ & 6.3 & 2.1 & 0.332 & Log-normal \\
& $\mathrm{f}_{\mathrm{u}}$ & $1.10 \cdot \mathrm{f}_{\mathrm{u}, \mathrm{n}}$ & $0.11 \cdot \mathrm{f}_{\mathrm{u}, \mathrm{n}}$ & 0.100 & Log-normal \\
& $\varepsilon_{\mathrm{u}}[\mathrm{mm} / \mathrm{mm}]$ & 0.24 & 0.14 & 0.579 & Normal \\
& $\mathrm{m}[-]$ & 4.2 & 1.9 & 0.462 & Log-normal \\
\hline Ferritic & $\mathrm{E}[\mathrm{MPa}]$ & 198572 & 15582 & 0.078 & Normal \\
cold-formed & $\mathrm{f}_{\mathrm{y}}$ & $1.30 \cdot \mathrm{f}_{\mathrm{y}, \mathrm{enh}, \mathrm{n}}$ & $0.195 \cdot \mathrm{f}_{\mathrm{y}, \mathrm{enh}, \mathrm{n}}$ & 0.150 & Log-normal \\
& $\mathrm{n}[-]$ & 10.1 & 5.4 & 0.536 & Log-normal \\
& $\mathrm{f}_{\mathrm{u}}$ & $1.10 \cdot \mathrm{f}_{\mathrm{u}, \mathrm{n}}$ & $0.11 \cdot \mathrm{f}_{\mathrm{u}, \mathrm{n}}$ & 0.100 & Log-normal \\
& $\varepsilon_{\mathrm{u}}[\mathrm{mm} / \mathrm{mm}]$ & 0.13 & 0.11 & 0.852 & Normal \\
& $\mathrm{m}[-]$ & 3.5 & 2.2 & 0.619 & Log-normal \\
\hline & & & & &
\end{tabular}


Table 8. Statistics of gravity loads for different design frameworks.

\begin{tabular}{|c|c|c|c|c|}
\hline $\begin{array}{c}\text { Design } \\
\text { framework }\end{array}$ & Load case & Mean & $\mathrm{COV}$ & $\begin{array}{c}\text { Statistical } \\
\text { distribution }\end{array}$ \\
\hline \multirow{2}{*}{$\begin{array}{l}\text { Eurocode } \\
\text { framework }\end{array}$} & Permanent load G & $1.0 \cdot \mathrm{G}_{\mathrm{k}}$ & 0.10 & Normal \\
\hline & Imposed variable load Q & $0.8 \cdot \mathrm{Q}_{\mathrm{k}}$ & 0.25 & Extreme Type I \\
\hline \multirow{2}{*}{$\begin{array}{c}\text { US } \\
\text { framework }\end{array}$} & Dead load D & $1.05 \cdot \mathrm{D}_{\mathrm{n}}$ & 0.10 & Normal \\
\hline & Imposed live load L & $1.0 \cdot \mathrm{L}_{\mathrm{n}}$ & 0.25 & Extreme Type I \\
\hline \multirow{2}{*}{$\begin{array}{l}\text { Australian } \\
\text { framework }\end{array}$} & Dead load G & $1.05 \cdot \mathrm{G}_{\mathrm{n}}$ & 0.10 & Normal \\
\hline & Imposed live load Q & $1.0 \cdot \mathrm{Q}_{\mathrm{n}}$ & 0.25 & Extreme Type I \\
\hline
\end{tabular}


Table 9. Summary of statistics for system strength of stainless steel frames under gravity loads.

\begin{tabular}{cccccccccc}
\hline Frame & $\begin{array}{c}\text { Nominal EN } \\
\text { resistance } \\
\mathrm{R}_{\mathrm{k}, \mathrm{EN}}[\mathrm{kN}]\end{array}$ & $\begin{array}{c}\text { Nominal US } \\
\text { resistance } \\
\mathrm{R}_{\mathrm{n}, \mathrm{US}}[\mathrm{kN}]\end{array}$ & $\begin{array}{c}\text { Nominal AU } \\
\text { resistance } \\
\mathrm{R}_{\mathrm{n}, \mathrm{AU}}[\mathrm{kN}]\end{array}$ & $\begin{array}{c}\text { Mean system } \\
\text { strength } \\
\mathrm{R}_{\mathrm{m}}[\mathrm{kN}]\end{array}$ & $\begin{array}{c}\text { COV of system } \\
\text { strength }\end{array}$ & $\mathrm{R}_{\mathrm{m}} / \mathrm{R}_{\mathrm{k}, \mathrm{EN}}$ & $\mathrm{R}_{\mathrm{m}} / \mathrm{R}_{\mathrm{n}, \mathrm{US}}$ & $\mathrm{R}_{\mathrm{m}} / \mathrm{R}_{\mathrm{n}, \mathrm{AU}}$ & $\begin{array}{c}\text { Statistical } \\
\text { distribution }\end{array}$ \\
\hline Frame 1 & 66.3 & 60.8 & 60.9 & 83.5 & 0.117 & 1.26 & 1.37 & 1.37 & Log-normal \\
Frame 2 & 101.9 & 94.4 & 95.6 & 120.5 & 0.113 & 1.18 & 1.28 & 1.26 & Log-normal \\
Frame 3 & 106.1 & 98.6 & 98.6 & 124.8 & 0.089 & 1.18 & 1.27 & 1.27 & Log-normal \\
Frame 4 & 140.7 & 131.4 & 131.4 & 166.5 & 0.114 & 1.18 & 1.27 & 1.27 & Log-normal \\
Frame 5 & 66.6 & 66.2 & 66.5 & 83.2 & 0.112 & 1.25 & 1.26 & 1.25 & Log-normal \\
Frame 6 & 101.0 & 102.4 & 101.0 & 120.5 & 0.111 & 1.19 & 1.18 & 1.19 & Log-normal \\
\hline
\end{tabular}


Table 10. Required system safety factors $\gamma_{\mathrm{M}, \mathrm{s}}$ and system resistance factors $\phi_{\mathrm{s}}$ for stainless steel frames under gravity loads (for $Q_{k} / G_{k}=2, L_{n} / D_{n}=2$ or $Q_{n} / G_{n}=2$ ) for different target reliability indices $\beta_{0}$ and different design frameworks. Eurocode framework US framework Australian framework

\begin{tabular}{|c|c|c|c|c|c|c|c|}
\hline Frame & $\begin{array}{c}\text { Reliability } \\
\text { index } \beta_{0}\end{array}$ & $\begin{array}{l}\text { Required system } \\
\text { safety factor } \gamma_{M, s}\end{array}$ & $1 / \gamma_{\mathrm{M}, \mathrm{s}} \sim \phi_{\mathrm{s}}$ & $\begin{array}{l}\text { Required system } \\
\text { resistance factor } \phi_{\mathrm{s}}\end{array}$ & $1 / \phi_{\mathrm{s}} \sim \gamma_{\mathrm{M}, \mathrm{s}}$ & $\begin{array}{l}\text { Required system } \\
\text { resistance factor } \phi_{\mathrm{s}}\end{array}$ & $1 / \phi_{\mathrm{s}} \sim \gamma_{\mathrm{M}, \mathrm{s}}$ \\
\hline \multirow{4}{*}{ Frame 1} & 3.8 & 1.10 & 0.91 & 0.83 & 1.21 & 0.79 & 1.27 \\
\hline & 3.3 & 0.97 & 1.03 & 0.94 & 1.06 & 0.90 & 1.11 \\
\hline & 3.0 & 0.90 & 1.11 & 1.02 & 0.98 & 0.97 & 1.03 \\
\hline & 2.5 & 0.79 & 1.26 & 1.16 & 0.86 & 1.11 & 0.90 \\
\hline \multirow{4}{*}{ Frame 2} & 3.8 & 1.17 & 0.86 & 0.77 & 1.29 & 0.73 & 1.37 \\
\hline & 3.3 & 1.03 & 0.97 & 0.88 & 1.13 & 0.83 & 1.20 \\
\hline & 3.0 & 0.95 & 1.05 & 0.95 & 1.05 & 0.90 & 1.11 \\
\hline & 2.5 & 0.84 & 1.19 & 1.08 & 0.92 & 1.02 & 0.98 \\
\hline \multirow{4}{*}{ Frame 3} & 3.8 & 1.13 & 0.89 & 0.80 & 1.25 & 0.76 & 1.31 \\
\hline & 3.3 & 1.00 & 1.00 & 0.91 & 1.10 & 0.86 & 1.16 \\
\hline & 3.0 & 0.93 & 1.08 & 0.98 & 1.02 & 0.93 & 1.07 \\
\hline & 2.5 & 0.82 & 1.21 & 1.11 & 0.90 & 1.06 & 0.95 \\
\hline \multirow{4}{*}{ Frame 4} & 3.8 & 1.17 & 0.86 & 0.77 & 1.30 & 0.73 & 1.37 \\
\hline & 3.3 & 1.03 & 0.97 & 0.88 & 1.14 & 0.84 & 1.20 \\
\hline & 3.0 & 0.95 & 1.05 & 0.95 & 1.06 & 0.90 & 1.11 \\
\hline & 2.5 & 0.84 & 1.19 & 1.08 & 0.93 & 1.03 & 0.97 \\
\hline \multirow{4}{*}{ Frame 5} & 3.8 & 1.10 & 0.91 & 0.76 & 1.31 & 0.73 & 1.38 \\
\hline & 3.3 & 0.97 & 1.03 & 0.87 & 1.15 & 0.83 & 1.21 \\
\hline & 3.0 & 0.90 & 1.11 & 0.94 & 1.06 & 0.89 & 1.12 \\
\hline & 2.5 & 0.80 & 1.26 & 1.07 & 0.94 & 1.02 & 0.98 \\
\hline \multirow{4}{*}{ Frame 6} & 3.8 & 1.15 & 0.87 & 0.72 & 1.40 & 0.69 & 1.44 \\
\hline & 3.3 & 1.02 & 0.98 & 0.82 & 1.22 & 0.79 & 1.27 \\
\hline & 3.0 & 0.94 & 1.06 & 0.88 & 1.13 & 0.85 & 1.17 \\
\hline & 2.5 & 0.83 & 1.20 & 1.00 & 1.00 & 0.97 & 1.03 \\
\hline
\end{tabular}

